\title{
Numerical Simulation for Flow of Rolling Piston Type of Rotary Compressor
}

\author{
Li-Chieh Hsu ${ }^{1}{ }^{*}$, Guo-Wei Wong ${ }^{1}$, Po-Jui Lu ${ }^{1}$, Fu-Shun Hsu ${ }^{2}$ and Ying-Chien Chen ${ }^{2}$ \\ 1 Department of Mechanical Engineering, National Yunlin University of Science and Technology, \\ 123 University Road, Section 3, Douliou, Yunlin 64002, Taiwan; M10411030@yuntech.edu.tw (G.-W.W.); \\ M10611031@yuntech.edu.tw (P.-J.L.) \\ 2 New Widetech Industries Co., Ltd.; Section B, 34FL. No. 16-1, Xinzhan Rd., Banqiao District, \\ New Taipei City 22041, Taiwan; fushun@newwidetech.com (F.-S.H.); juian@newwidetech.com (Y.-C.C.) \\ * Correspondence: edhsu@yuntech.edu.tw
}

Received: 7 April 2020; Accepted: 11 May 2020; Published: 16 May 2020

\begin{abstract}
In this numerical study, the temperature, pressure and flow structure inside the rotary compressor are obtained to analyze the work consumption and efficiency. The geometry of the compressor such as volume, inlet angle, and mass of reed valve are varied to look for optimal performance and design margin as the suggestions for manufacturing. The work done on refrigerant increases proportionally with the volume of the compressor. However, there is an optimal volume for efficiency. The design margin for inlet angle is determined. The best efficiency exists in a specific inlet angle. Larger mass of reed valve leads to the increase of input power due to the additional resistance from greater inertia, which causes a decrease of efficiency. The flow visualization by simulation diagnoses the potential factors, which may cause noise problem.
\end{abstract}

Keywords: rotary compressor; rolling piston; numerical; inlet; compression volume; reed valve

\section{Introduction}

The experimental methods for compressors usually only provide the thermodynamic properties such as the discharge pressure, temperature, or enthalpy difference between inlet and outlet, and work, etc. However, some microscopic problems, such as the leakage from the gap between the sliding blade and rolling piston, or the gap between the piston and the wall of the cylindrical chamber, motions of the sliding blade, response of reed valve, and flow structures inside the chamber-all of which affect the compression efficiency-are hard to be detected with the experimental approach. Hence, computational fluid dynamics (CFD) provides an option to scrutinize the flow structure inside a compression chamber and study the critical parameters and issues, including the compression volume, inlet angle, openness, and response of reed valve and leakage, which affect the efficiency of compressor.

The cooling capacity and input power can be simulated precisely by using the CFD method [1,2] with a deviation of less than $10 \%$ from an actual experimental result. However, the flow structure inside the compression chamber is still unknown. The suction volume of a rolling piston rotary compressor is determined by its major dimensions, such as rolling piston diameter, cylinder depth, and cylinder bore. The suction volume may affect the mechanical efficiency. Ishii et al. [3] theoretically studied the optimal mechanical efficiency by using many combinations of major dimensions that yield a rolling piston rotary compressor with the same suction volume. First, they used the combination of different radii of piston and depth of cylinder with the same radius of cylinder to ensure constant suction volume. Their result shows the optimal mechanical efficiency exists as the radius of piston is at $1.5 \mathrm{~cm}$. They also used three different radii of cylinder to determine the optimal efficiency for each radius of cylinder by changing the associated radius of piston and depth of cylinder, while maintaining a constant suction 
volume. They also changed suction volume with various combinations of different radii of piston, and depth of cylinder, for a given radius of cylinder. The results show the optimal mechanical efficiency exists in a specific radius of piston and its corresponding depth of cylinder in each suction volume. In their studies, at least two parameters are changed. However, it is hard to find out the factor that really affects the efficiency. Therefore, in this study, only one parameter, the radius of piston, is changed with constant radius and depth of cylinder to determine the volume effect on efficiency.

Other major dimensions, such as slenderness ratio $(\mathrm{H} / \mathrm{D})$, which is the ratio of the depth of cylinder to the diameter of cylinder, also affect the mechanical efficiency. Noh et al [4] conducted experiments and numerical analyses to improve compressor efficiency in low speed regions under various pressure conditions. Their results show the effect of cylinder slenderness ratio $(\mathrm{H} / \mathrm{D})$ is very sensitive at high compression ratio conditions. The volumetric efficiency and cooling capacity at small cylinder slenderness ratio can be increased with minor increase of input work due to the low leakage and more intake flow.

In addition to the major dimensions of compressor already discussed, the efficiency is also affected by the sizes of other subcomponents. Bolloju et al. [5] numerically studied the effect of the port size on the performance of compressor. Their results show that as the size of discharge port increases, the cooling capacity decreases, but energy efficiency ratio (EER) increases. However, the input power from motor decreases obviously as discharge port size increases. The conclusion from numerical simulation is consistent with that from the experiment. Tan et al. [6] studied the effect of effective flow area and effective force area of the reed valve on the performance of a rotary compressor with two fluid-structure interaction (FSI) models by using the commercial multiphysics code, ADINA. The effective force area associates with the pressure drop across the valve and the gas force acting on the valve surface. The precision of the valve model depends largely on the accuracy of effective flow and force areas. Their conclusion indicates the precise effective flow area and force area can avoid underestimation of the flow energy loss through the discharge port. Brancher and Deschamps [7] used Ansys CFX to develop a prediction method for calculation of effective flow and force area coefficients of rolling piston compressors. The result shows the $\mathrm{p}-\mathrm{V}$ diagram obtained from the prediction method agrees well with that from measurement. In addition, the agility of reed valve also affects the effective flow area. Prater and Hnat [8] used an optical measurement technique to measure the fundamental undamped natural frequency and damping ratio for the discharge reed valve in a rolling piston rotary compressor. The measured stiffness, fundamental natural frequency, and equivalent viscous damping ratio were incorporated as valve model parameters in a comprehensive computer simulation program for the compressor. Their results show that the natural frequency of a reed valve is a strong function of preload geometry. Lubricant viscosity and retaining screw torque had little effect on the modal parameters.

Pressure pulsation and leakage are other challenges for compressor design. Liu and Geng [9] numerically studied the performance of a two-cylinder type rolling piston compressor. Two models that had separate suction piping system and common suction piping system were compared. In the separate suction piping system, two suction pipes were connected from the accumulator to each cylinder separately. For the common suction piping system, suction pipes were connected commonly from the accumulator to the cylinders. Their numeric al results and the experimental data show that the system with common suction pipe noticeably reduces the noise level due to the attenuating of pressure pulsations. Cai et al. [10] numerically studied the difference of leakage losses characteristics between R290 and that of other refrigerants, such as R22 and R410a. The results showed that smaller radial clearance was required for R290 to obtain relatively high efficiency compared to that of R22 and R410a under the same condition.

For comprehensive consideration of compressor design, Ooi [11] developed an optimization algorithm to search for a combination of some design dimensions and constraints for an optimum compressor performance with minimum mechanical losses. The model accounts for geometrical configuration, thermodynamics effects, valve dynamics, flow, and mechanical considerations. The results showed for a given compressor swept-volume, a proper combination of the compressor 
design dimensions could lead to a $50 \%$ reduction in mechanical loss and a $14 \%$ increase in the coefficient of performance.

For different compression requirements, the working volume is demanded to increase without changing the external dimension due to the limited space inside an air conditioner. In addition, for some manufacturing reasons, the inlet angle usually demands to be deviated away from the sliding blade with enough distance. The reed valve is preferably made more hardened for extending its lift cycle. Those demands from the manufacturing may need to change the dimension of components, geometry, or material. Hence, in this study, the effects of working volume, inlet angle, and material of reed valve on the thermal properties and efficiency of compression have to be investigated. The approach is outlined here. The CFD technique is used to simulate flow structure. The pressure, temperature, and mass flow rate of refrigerant are obtained for analyses of the work done on refrigerant and the efficiency of compressor. The working volume of compressor is adjusted by changing the diameter of piston to determine the optimal performance. The inlet angle of compressor and mass of reed valve are varied substantially to investigate the effects on efficiency and the design margins of rolling piston type of rotary compressor.

\section{Numerical Method}

The CFD package PumpLinx (Bellevue, WA, USA), a finite volume approach, is used to solve the equations for conservation of mass, momentum, and energy of a compressible fluid. Those conservation laws can be written in integral expressions as the follows.

continuity:

$$
\frac{\partial}{\partial t} \int_{\mathrm{V}} \rho d \mathrm{~V}+\int_{S} \rho\left(\boldsymbol{v}-\boldsymbol{v}_{\sigma}\right) \cdot n d S=0
$$

momentum:

$$
\frac{\partial}{\partial t} \int_{\mathrm{V}} \rho v d \mathrm{~V}+\int_{S} \rho\left(\left(\boldsymbol{v}-\boldsymbol{v}_{\sigma}\right) \cdot \boldsymbol{n}\right) v d S=\int_{S} \tilde{\boldsymbol{\tau}} \cdot \boldsymbol{n} d S-\int_{S} p \boldsymbol{n} d S+\int_{V} f d \mathrm{~V}
$$

energy:

$$
\begin{gathered}
\frac{\partial}{\partial t} \int_{\mathrm{V}} \rho E d \mathrm{~V}+\int_{S} \rho\left(\left(\boldsymbol{v}-\boldsymbol{v}_{\sigma}\right) \cdot \boldsymbol{n}\right) E d S \\
=\int_{S} k \nabla T \cdot \boldsymbol{n} d S-\int_{S} p \boldsymbol{v} \cdot \boldsymbol{n} d S+\int_{S}(\boldsymbol{v} \cdot \widetilde{\boldsymbol{\tau}}) \cdot \boldsymbol{n} d S+\int_{\mathrm{V}} f \cdot \boldsymbol{v} d \mathrm{~V}
\end{gathered}
$$

where $\mathrm{V}$ is control volume, $\mathrm{S}$ is the surface of control volume, $\mathrm{V}$ and $\mathrm{S}$ both are time dependent, $\mathrm{n}$ is the surface normal pointed outwards, $\rho$ is the fluid density, $\mathrm{p}$ is the pressure, $\mathrm{f}$ is the body force, $\mathrm{E}$ is total energy, $k$ is thermal conductivity, $v$ is the fluid velocity, $v_{\sigma}$ is the mesh velocity, $\widetilde{\tau}$ is the shear stress tensor.

The shear stress tensor $\tilde{\tau}$ is a function of the fluid viscosity $\mu$ and of the velocity gradient; for a Newtonian fluid, this is given by the following equation

$$
\tau_{i j}=\mu\left(\frac{\partial u_{i}}{\partial x_{j}}+\frac{\partial u_{j}}{\partial x_{i}}\right)-\frac{2}{3}\left(\frac{\partial u_{k}}{\partial x_{k}}\right) \cdot \delta_{i j}
$$

where $\mathrm{u}_{\mathrm{i}}(\mathrm{i}=1,2,3)$ is the velocity component, $\delta_{i j}$ is the Kronecker delta function.

The standard two-equation model $k-\varepsilon[12]$ is used to account for turbulence,

$$
\begin{gathered}
\frac{\partial}{\partial t} \int_{\mathrm{V}} \rho k d \mathrm{~V}+\int_{S} \rho\left(\left(\boldsymbol{v}-\boldsymbol{v}_{\sigma}\right) \boldsymbol{n}\right) k d S=\int_{S}\left(\mu+\frac{\mu_{t}}{\sigma_{k}}\right)(\nabla k \boldsymbol{n}) d S+\int_{\mathrm{V}}\left(G_{t}-\rho \epsilon\right) d \mathrm{~V} \\
\frac{\partial}{\partial t} \int_{\mathrm{V}} \rho \epsilon d \mathrm{~V}+\int_{S} \rho\left(\left(\boldsymbol{v}-\boldsymbol{v}_{\sigma}\right) \boldsymbol{n}\right) \varepsilon d S=\int_{S}\left(\mu+\frac{\mu_{t}}{\sigma_{\varepsilon}}\right)(\nabla \epsilon \boldsymbol{n}) d S+\int_{\mathrm{V}}\left(c_{1} G_{t} \frac{\varepsilon}{k}-c_{2} \rho \frac{\varepsilon^{2}}{k}\right) d \mathrm{~V}
\end{gathered}
$$

where $\rho=\mathrm{f}(\mathrm{T}, \mathrm{P}), c_{1}=1.44, c_{2}=1.92, \sigma_{k}=1, \sigma_{\varepsilon}=1.3$; where $\sigma_{k}$ and $\sigma_{\varepsilon}$ are the turbulent kinetic energy and the turbulent kinetic energy dissipation rate Prandtl numbers. 


\section{Model and Boundary Conditions}

The geometry of the computational model is the same as for a real device as shown in Figure 1. The compressor is composed of a cylinder with inlet and discharge port, an eccentric rotary piston, a sliding blade, and a reed valve on discharge port as shown in Figure 1a. The piston rotates in counterclockwise at $3450 \mathrm{rpm}$ with eccentricity, $0.002565 \mathrm{~m}$, with respect to the center of cylinder. The gap between piston and sliding blade is kept at $3 \times 10^{-7} \mathrm{~m}$. The moment inertia of reed valve is $1.09 \times 10^{-7} \mathrm{~kg} \cdot \mathrm{m}^{2}$. The longitudinal axis of reed valve deviates from the centerline of cylinder at $49^{\circ}$ as shown in Figure 1b. The circular area of reed valve covers the discharge port. Between cylinder and reed valve, there is a transitional slope, which gradually changes the flow direction from the radial direction to the perpendicular as shown in Figure 1c. Form the top-down view of the cylinder, the transitional slope appears as a semicircle, a so-called oblique incision, shown in Figure 1a. The gap between the semicircular discharge port and reed valve in its closed position is $1.5 \times 10^{-6} \mathrm{~m}$, to mimic the real condition that arises under manufacturing constraints.

The inlet boundary is set with a pressure of $9 \mathrm{~atm}$ at a temperature of $35^{\circ} \mathrm{C}$, according to the experimental conditions. A sufficient large computational domain is set to connect with the discharge port to contain the whole moving trace of the reed valve as shown in Figure 1f, which shows a boundary condition is set on the top of this computational domain with pressure $32 \mathrm{~atm}$ to simulate the backpressure in the real circumstances.

\subsection{Meshes}

Deforming meshes are employed inside cylinder where meshes are expanded at the suction chamber and compressed at the compression chamber as sown in Figure 2a. The nonconforming meshes are employed in the region near the upper surface of the reed valve and the interface between the moving reed valve and ambient area above the discharge port as shown in Figure $2 b$. The meshes beneath and above reed valve are deformable.

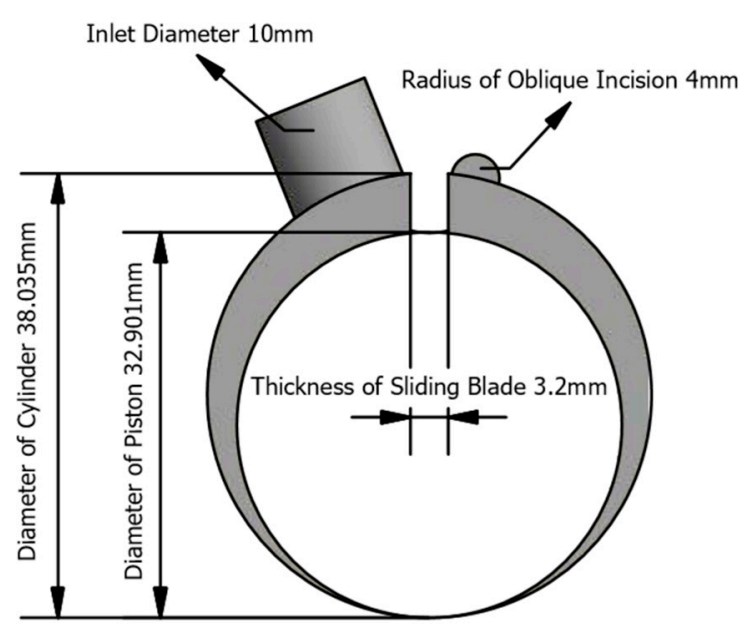

(a)

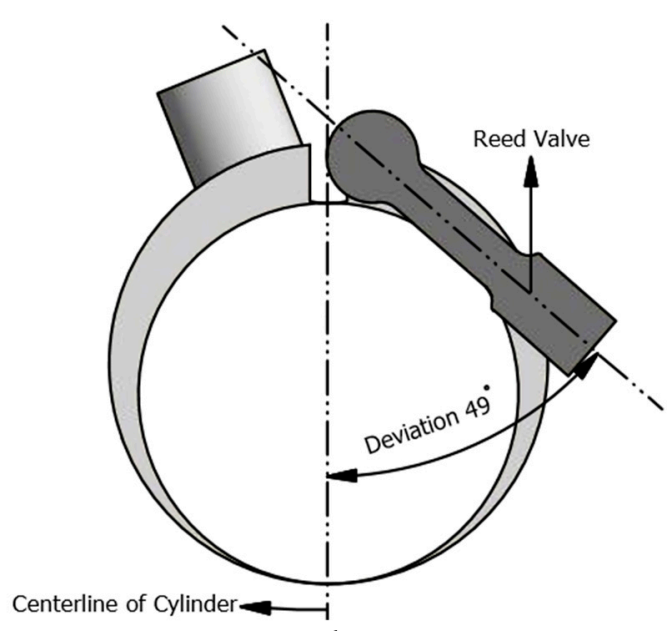

(b)

Figure 1. Cont. 


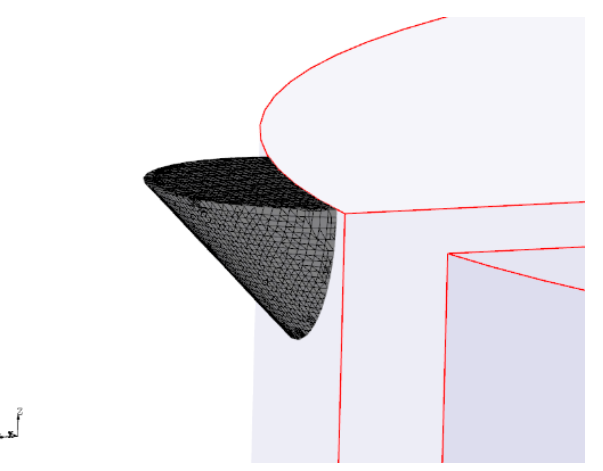

(c)

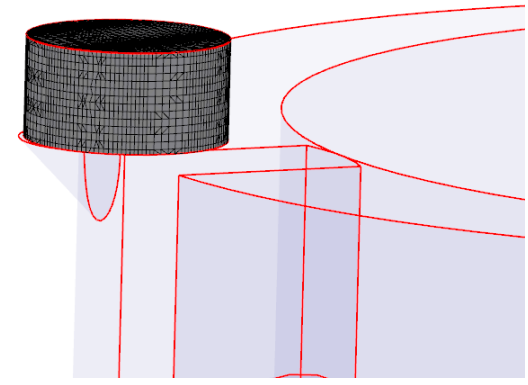

(e)

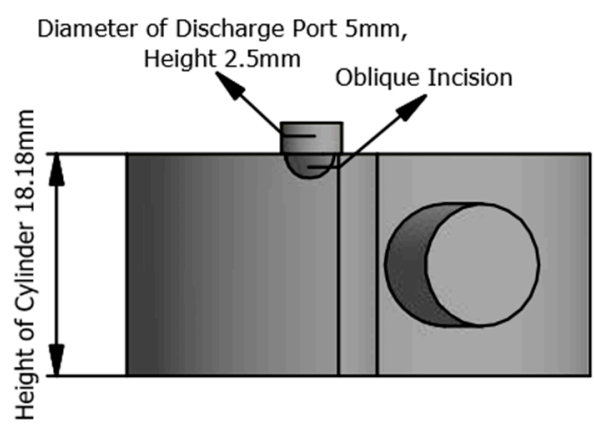

(d)

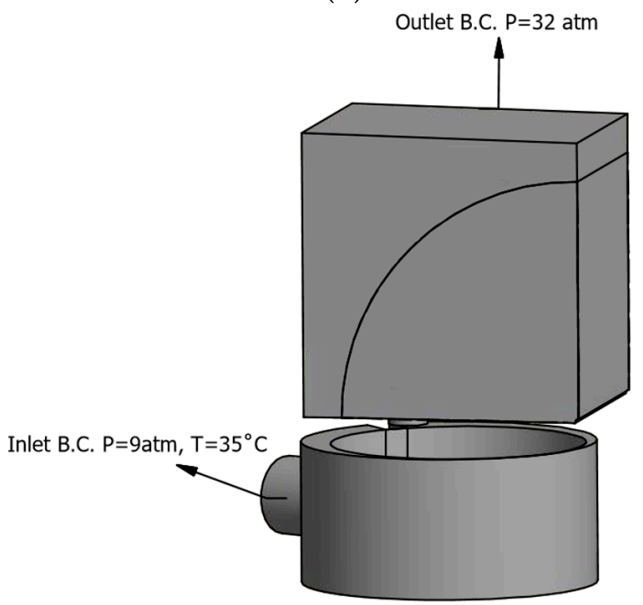

(f)

Figure 1. Geometry of Model and boundary conditions: (a) basic profile of the compressor; (b) location of reed valve, (c) oblique incision; (d) side view of the compressor $€$ discharge port; (f) boundary conditions.

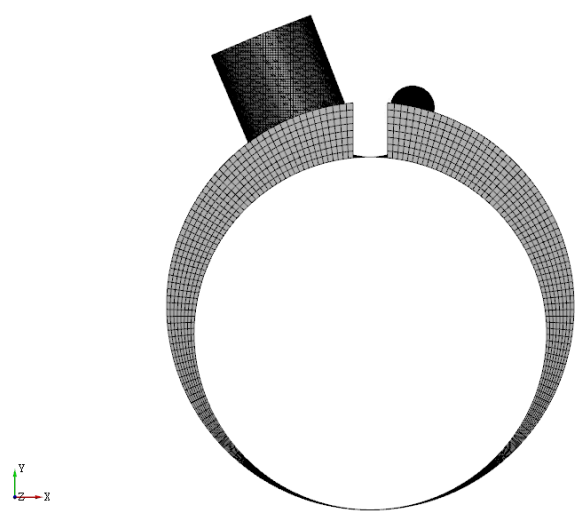

(a)

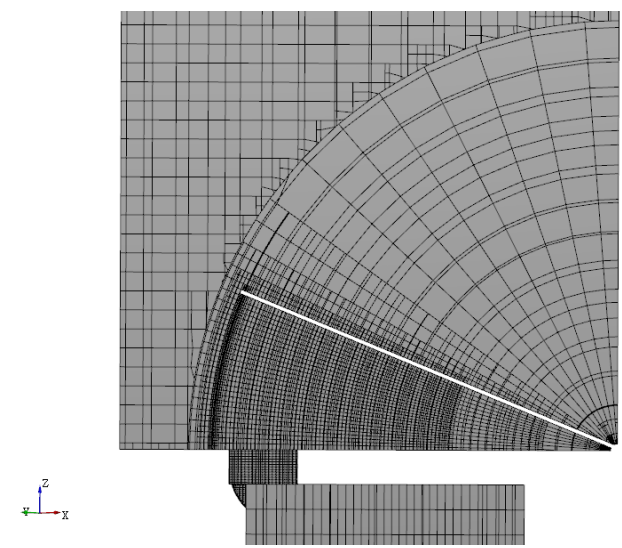

(b)

Figure 2. Mesh type and distribution: (a) meshes inside cylinder, (b) meshes beneath and above reed valve.

\subsection{Reed Valve Motion}

In this simulation, the reed valve is modeled as a gate which one end connects with the upper surface of the compressor with a hinge and other end is free. The rotational axis of hinge is parallel to the $\mathrm{X}-\mathrm{Y}$ plane as shown in Figure $1 \mathrm{~b}$. The valve is opened toward the positive Z-direction as shown in Figure $2 \mathrm{~b}$. The valve opening angle, $\beta$, is the angle between reed valve and discharge port of 
compressor as shown in Figure 2b. For simplicity, the deflection of valve is neglected. $I$ is the moment of inertia of the valve, $\tau$ is the torque from fluid forces, and $t$ is time. Therefore, the motion equation of valve can be modelized as Equation (7)

$$
I \frac{d^{2} \theta}{d t^{2}}=\tau(t)
$$

$I$ is determined by the material and dimension of the reed valve according to the information provided by the manufacturer. $\tau$ is determined by the instantaneous pressure difference between the surfaces beneath and above reed valve. Once the instant torque and moment of inertia are determined, the instantaneous acceleration of reed valve can be calculated. Hence, the motion of reed valve can be described.

\subsection{Measured Point}

Although the physical properties are measured at many different locations as Figure 3, only three representative measured points are used. The first point, Inlet 1 , is set at the center of the cylindrical inlet port and beneath the rim of inlet with $3 \mathrm{~mm}$ where inlet mass flow rate and suction pressure are measured as shown in Figure 3a. The second point, Inner 2, is set at the same angular position with oblique incision and above the bottom of cylinder with height of $9.09 \mathrm{~mm}$ to determine the inner pressure of compression chamber as shown in Figure 3a,b. The third point, Outlet 3, is at the center of semicircular oblique incision where the discharge pressure and mass flow rate are measured as shown in Figure 3c. Notably, the semicircular oblique incision is the only outlet of this compressor. Figure $3 \mathrm{~d}$ shows the assembled real parts, which include cylinder, piston, shaft, and sliding blade. The physical properties will be measured on these three representative locations in the following simulations.

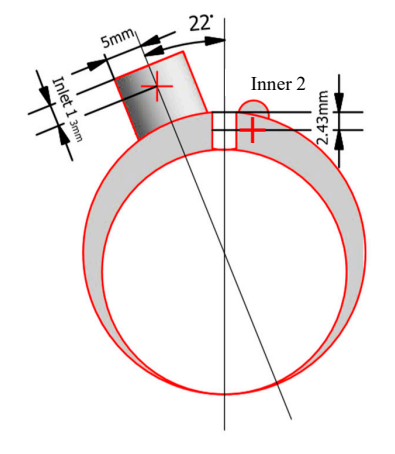

(a)

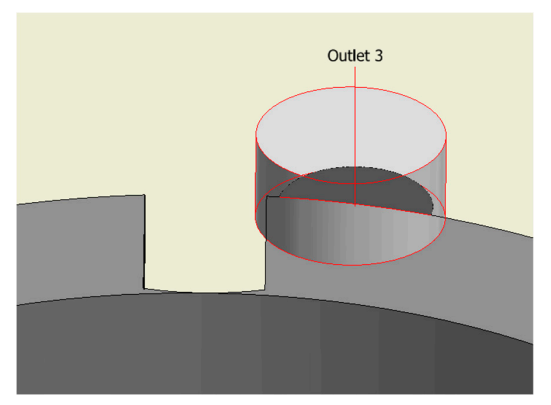

(c)

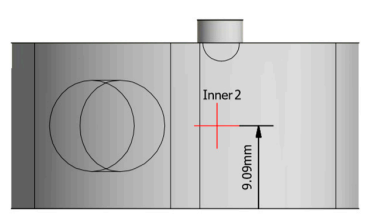

(b)

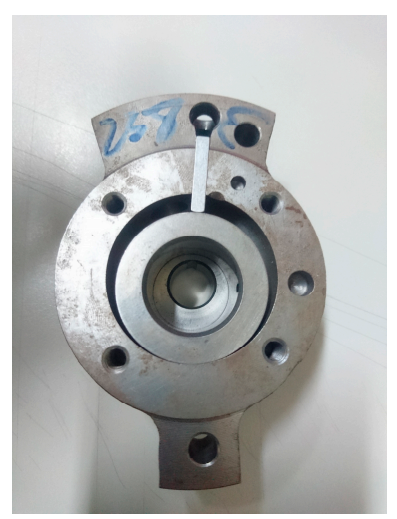

(d)

Figure 3. The locations of three representative measured points (a) Inlet 1, (b) Inner 2, (c) Outlet 3 (d) assembly of real parts. 


\subsection{Grid Independence}

The mass flow rate at the discharge port for each rotation angle of the piston shown in Figure 4a is convergent if the number of meshes exceeds 660,984 . The pressure inside the compression chamber is also convergent when the number of meshes is larger than 660,984 as shown in Figure $4 \mathrm{~b}$. Therefore, for considering the sufficient number of meshes and cost of computation, the number of meshes of the model is built about 660,984 for the following simulations.

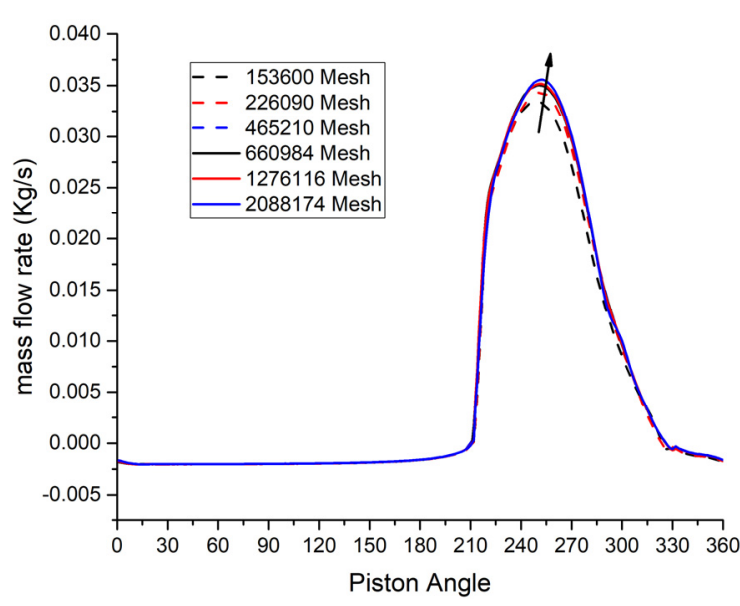

(a)

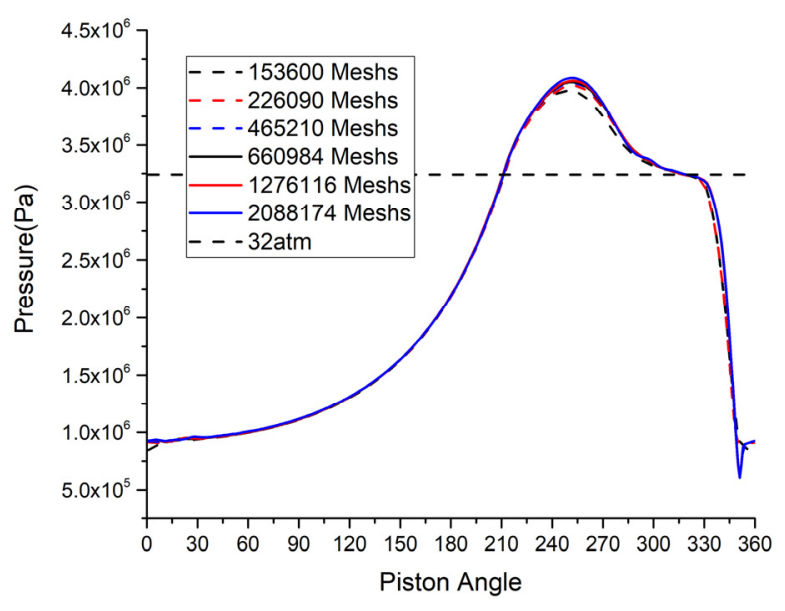

(b)

Figure 4. Grid independence test (a) discharge mass flow rate (at Outlet 3) at each rotation angle of piston with different number of meshes, (b) pressure of compression chamber at Inner 2 with different number of meshes.

\subsection{Validation}

Two models of compressor which compression volumes are $5.2 \mathrm{~cm}^{3}$ and $4.9 \mathrm{~cm}^{3}$, respectively, are tested experimentally and numerically for validation. Notably, there are different inlet conditions, including temperature and pressure in the two test models. The refrigerant, R410a, is used in experiment and simulation. The properties of R410a for simulation, including density, viscosity, enthalpy, and thermal conductivity are built in advance with mini-REFPROP (Gaithersburg, MD, USA, a software developed by National Institute of Standards and Technology [13] for looking up the properties of refrigerants. After the completed databank of R410a properties (which are the function of pressure and temperature) are established, the databank is loaded into the PumpLinx for further simulations of compression.

\subsubsection{Test Rig}

The test is conducted according to ISO 917-1974, an international standard, for testing compressor of refrigeration with a testing facility as shown in Figure 5a. The testing equipment is designed base on the secondary refrigerant calorimeter method. The arrangement of major components, including compressor, accumulator, evaporator, water-cool condenser, expansion valve, two main pipelines, which are discharge pipe and returning pipe and sensors is shown in Figure 5a and Table 1. The schematic diagram of the test loop can be described as Figure $5 b$.

Inside the test room, the room ambient temperature is controlled by a fan. The temperature and pressure of the condenser are controlled by a water-cooling system. The temperature and pressure of vaporized refrigerant is controlled by a calorimeter for desired inlet conditions, $35^{\circ} \mathrm{C}, 0.995 \mathrm{Mpa}$ for Model 1 or $24^{\circ} \mathrm{C}, 1.149 \mathrm{Mpa}$ for Model 2. The thermocouples and pressure transducers are employed at the inlet and outlet of compressor with accuracy $\pm 0.1 \mathrm{C}$ for temperature and the errors of absolute pressure or pressure difference measurement less than $\pm 1 \%$. The completed measurement accuracy is listed in Table 2. 


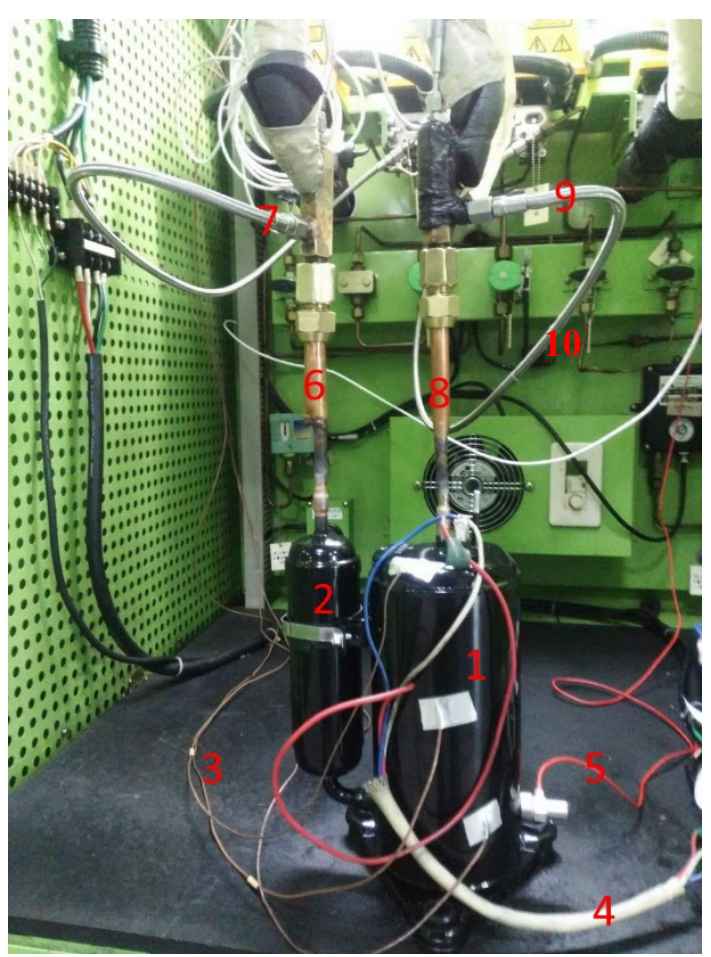

(a)

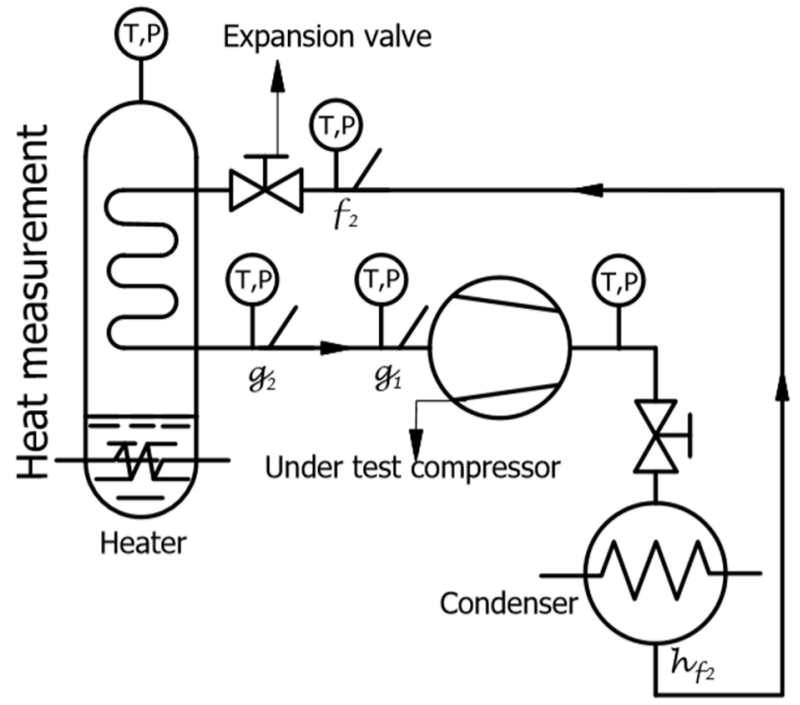

(b)

Figure 5. Compressor test rig: (a) facility (b) arrangement.

Table 1. Major components of testing facility.

\begin{tabular}{ccc}
\hline Item No. & Description & Function \\
\hline 1 & Compressor & Tested model \\
\hline 2 & Accumulator & Separate vapor and liquid phase of refrigerant \\
\hline 3 & Thermocouple & Monitor compressor for preventing from overheat \\
\hline 4 & Wire of power supply & Provide power for motor \\
\hline 5 & Magnetic pickup tachometer & Detect rotational speed of shaft \\
\hline 6 & Returning pipe (from evaporator) & Connect evaporator to accumulator \\
\hline 7 & Resistance Temperature Detector & Detect temperature of vapor from evaporator \\
\hline 8 & Discharge pipe (to the condenser) & Connect compressor outlet to condenser \\
\hline 9 & Resistance Temperature Detector & Detect discharged vapor temperature \\
\hline 10 & Condenser, evaporator & Heat exchange (inside a wall of the test rig) \\
\hline
\end{tabular}

As shown in Figure 5a, the motor driven-compressor inside an enclosure to compress the vaporized refrigerant, R410a, to the rated pressure, 3.348 Mpa or 2.271 Mpa. The higher-pressure refrigerant goes through the discharge pipe to the condenser where refrigerant is condensed completely. The condensed refrigerant flows through the throttle valve and enters the evaporator or heater in the calorimeter as shown in Figure 5b. The evaporated refrigerant flows through the returning pipe to an accumulator where the vapor phase and liquid phase of refrigerants are separated to prevent liquid phase of refrigerant from entering the compressor. After this, the vaporized refrigerant flows back to the compressor, again. The calorimeter and condenser are hard to be identified from the Figure 5a, because both are installed inside a wall of the test room. The numerical simulations are conducted according to the inlet conditions and shaft rotational speed of the tested models defined. 
Table 2. Measurement accuracy.

\begin{tabular}{ccc}
\hline Parameters & Accuracy & Sensor Type \\
\hline Temperature & $\pm 0.1^{\circ} \mathrm{C}$ & Resistance thermometers \\
\hline Pressure & $\pm 1 \%$ & Pressure transducer \\
\hline Liquid mass flow rate & $\pm 1 \%$ & Turbine flow meter \\
\hline Gas mass flow rate & $\pm 2 \%$ & Turbine flow meter \\
\hline Input power & $\pm 1 \%$ & Rotary torque sensor, voltage, and current meters \\
\hline Shaft rotational speed & $\pm 1 \%$ & Magnetic pickup tachometer \\
\hline
\end{tabular}

\subsubsection{Validation Results}

Table 3 shows all deviations between experimental and numerical primary physical property including the mass flow rate of refrigerant, enthalpies at inlet/outlet, which are less than $0.7 \%$. The transient work done on refrigerant is calculated by Equation (8) with primary data of mass flow rate and enthalpy. The mean work done on refrigerant is obtained by taking integral of transient work done on refrigerant and dividing this by the time of a compression cycle as shown in Equation (9). This calculated property may cause slightly larger errors of approximately $2.350 \%$ for Model 1 , and $0.235 \%$ for Model 2. Besides, the boundary conditions of inlet pressure and backpressure for Model 1 are set with some deviation from the experimental ones due to considering the difference of measured locations between experiment and simulation. For Model 2, the measurement obstacles were resolved; therefore, the boundary conditions were in keeping with the experimental ones.

Table 3. The comparison of experimental and numerical results.

\begin{tabular}{|c|c|c|c|c|c|c|}
\hline \multirow{2}{*}{ Physical Properties } & \multicolumn{3}{|c|}{ Model 1 (Compression Volume $5.2 \mathrm{~cm}^{3}$ ) } & \multicolumn{3}{|c|}{ Model 2 (Compression Volume $4.9 \mathrm{~cm}^{3}$ ) } \\
\hline & Experiment & Simulation & Deviation (\%) & Experiment & Simulation & Deviation (\%) \\
\hline Working fluid & R410a & $\mathrm{R} 410 \mathrm{a}$ & & $\mathrm{R} 410 \mathrm{a}$ & R410a & \\
\hline Inlet temperature $\left({ }^{\circ} \mathrm{C}\right)$ & 35 & 35 & & 24.0 & 24.0 & 0 \\
\hline $\begin{array}{l}\text { Rotational speed of } \\
\text { compression (rpm) }\end{array}$ & 3450 & 3450 & 3450 & 3450 & 3450 & \\
\hline Outlet pressure (abs Mpa) & 3.348 & 3.242 & -3.1 & 2.721 & 2.721 & 0 \\
\hline Outlet temperature $\left({ }^{\circ} \mathrm{C}\right)$ & 110.06 & 109 & 1.8 & 75.75 & 75 & 0.9 \\
\hline Mass flow rate $(\mathrm{kg} / \mathrm{hr})$ & 30.43 & 30.2731 & 0.515 & 37.48 & 37.5871 & 0.26 \\
\hline $\begin{array}{l}\text { The enthalpy of refrigerant } \\
\text { at inlet }(\mathrm{kJ} / \mathrm{kg})\end{array}$ & 453.17 & 456.202 & -0.669 & 438.250 & 440.033 & 0.41 \\
\hline Input power & 617 & 610.138 & 1.112 & 525 & 502.93 & 4.2 \\
\hline Overall efficiency & 70.89 & 69.632 & 1.774 & 63.3 & 66.2 & 4.7 \\
\hline
\end{tabular}

transient work rate done on refrigerant at a rotation angle of piston is given by Equation (8)

$$
\dot{W}=\dot{m}\left(h_{\text {out }}-h_{\text {in }}\right)
$$

mean work rate done on refrigerant of a cycle is given by Equation (9)

$$
\overline{\dot{W}}=\frac{1}{T_{0}} \int_{0}^{T_{0}} \dot{W} \mathrm{dt}
$$


where $T_{0}$ is the period of a cycle. The shaft power is given by Equation (10).

$$
\overline{W_{\text {shaft }}}=\frac{1}{T_{0}} \int_{0}^{2 \pi} T(\theta) \mathrm{d} \theta
$$

where $T(\theta)$ is the torque from shaft at a rotation angle of piston. The torque, $T(\theta)$, can be obtained by the fluid forces acting on the piston in simulation because the rotating piston is driven by shaft. The actual input power from the original electrical power is decayed due to the motor conversion and shaft transmission. The conversion efficiency of motor is between 0.9 and 0.95 , which depends on the age of using. The shaft transmission efficiency, $\eta_{\text {shaft }}$, is measured by torque sensors for the shaft, which connects motor and compressor. Hence, $\eta_{\text {shaft }}$ were determined to be 0.8 after few trials. With measured $\eta_{\text {shaft }}$ and $\eta_{\text {motor }}$, the numerical input power for each case was calculated by using Equation (11). For experiments, the actual input power is measured from experimental voltage and current readings. The actual work done on refrigerant can be obtained from the mass flow rate and the difference of enthalpy between inlet and outlet by using Equations (8) and (9).

The estimated or numerical input power is given by Equation (11)

$$
\overline{W_{\text {in }}}=\frac{1}{T_{0}} \int_{0}^{2 \pi} T(\theta) \mathrm{d} \theta \cdot \frac{1}{\eta_{\text {shaft }}} \cdot \frac{1}{\eta_{\text {motor }}}
$$

once the mean work rate done on refrigerant and input power are obtained, the overall efficiency can be calculated by using Equation (12) for experiment and simulation, respectively.

The overall efficiency is shown as Equation (12).

$$
\eta_{\text {overall }}=\frac{\overline{\bar{W}}}{\overline{\dot{W}_{\text {in }}}}
$$

hence, Table 2 demonstrate the sufficient accuracy of the numerical approach with this numerical scheme, computational domain, number of meshes and boundary conditions.

\section{Results and Discussion}

\subsection{Basic Type}

The centerline of inlet port deviates from the sliding blade at an angle, inlet angle, denoted, $\alpha$. The basic type of compressor was model 2210-45 where the first two digits of the model number indicate the inlet angle, $\alpha=22$, as shown in Figure 3a. The modified models have model numbers that follow the same pattern. Figure 6 shows how piston rotates in counterclockwise and sliding blade move forward and backward in a slot on the cylinder wall according to the position of piston. The piston rotates from $\theta=0$ to $360^{\circ}$ at $3450 \mathrm{rpm}$. As $\theta=0$, the sliding blade immerses into the wall of cylinder, there is a small amount of leakage between the piston and the wall of cylinder. When rotation angle of piston is greater than 40 , the suction motion begins. As $\theta=80$, the piston obviously separates the chamber into suction and compression. After one revolution, the temperature of refrigerant is increased from $308.15 \mathrm{k}$ at the inlet (ambient temperature) to $400 \mathrm{k}$ due to compression.

The boundary condition of ambient pressure at the inlet is set as $911.925 \mathrm{kPa}$. As the rotation angle of rolling piston is increased to $\theta=180$, the pressure at Inlet 1 drops to $910.447 \mathrm{kPa}$. The pressure drop generates the maximum suction pressure as shown in Figure 7a. At this moment, the mass flow rate at inlet reaches a maximum. Once the rotation angle exceeds $180^{\circ}$, the suction pressure and mass flow rate at inlet gradually decline. While the rotation angle is between $354^{\circ}$ and $24^{\circ}$, the pressure at Inlet 1 is slightly above the inlet ambient pressure. Within this range of angles, the mass flow rate 
is negative which means refrigerant flows out of the compressor. Refrigerant is pushed out by the motion of rolling piston within this range of angles. Meanwhile, the leakage between piston and sliding blade also assists to flow out. The refrigerant is still under higher pressure ( $>3242.400 \mathrm{kPa}$ ) and leaves through the gap between the piston and sliding blade from the compression chamber to the suction chamber $(<911.925 \mathrm{kPa})$. Finally, the leaking refrigerant with higher-pressure flows out of inlet as the piston rotates.

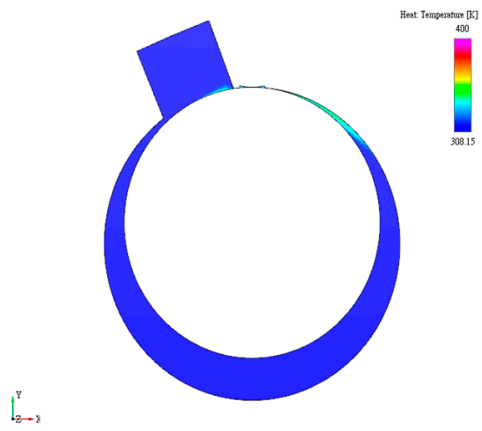

(a)

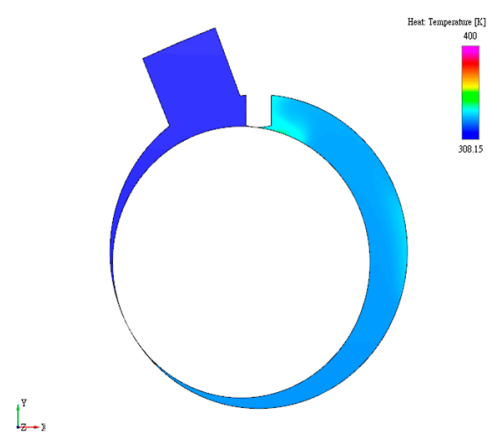

(d)

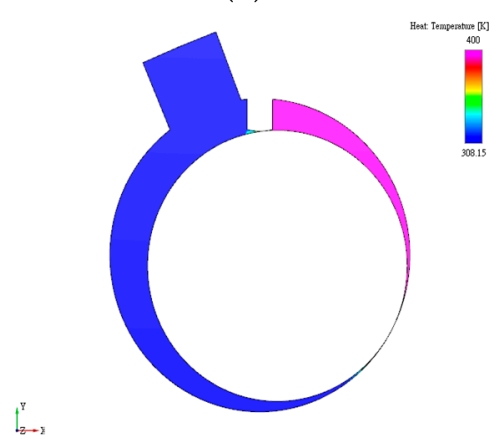

(g)

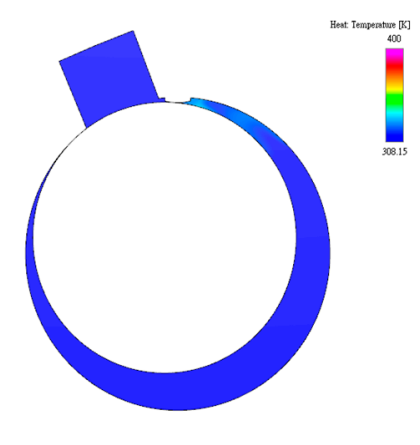

(b)

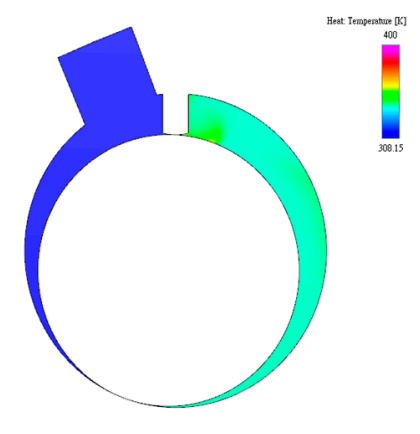

(e)

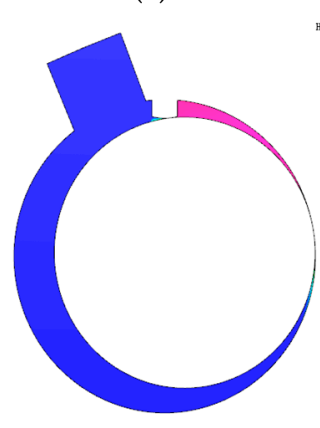

(h)

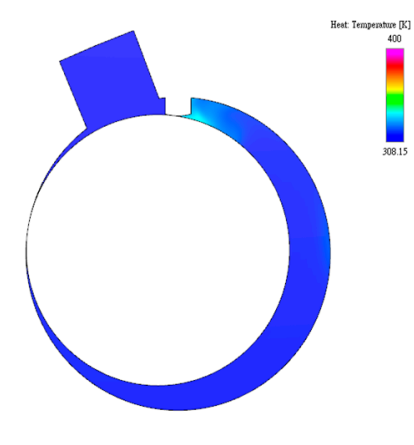

(c)

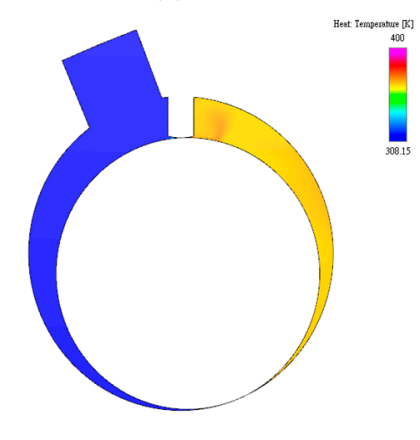

(f)

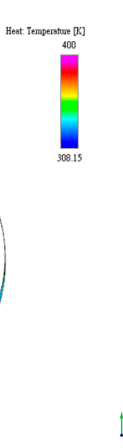

$L_{z \rightarrow 8}^{8}$

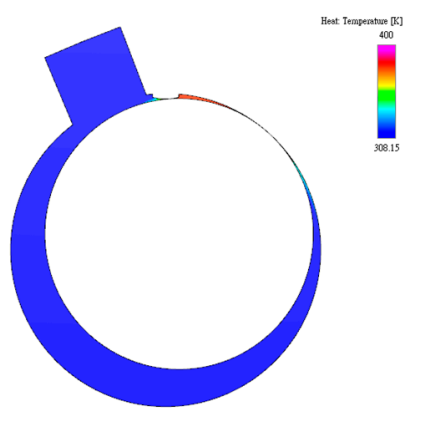

(i)

Figure 6. Temperature distribution at different rotation angles of piston: (a) $0^{\circ}$, (b) $40^{\circ}$, (c) $80^{\circ}$, (d) $120^{\circ}$, (e) $160^{\circ}$, (f) $200^{\circ}$, (g) $240^{\circ}$, (h) $280^{\circ}$, (i) $320^{\circ}$.

To open the reed valve on the discharge port, the pressure inside the compression chamber must be larger than the backpressure, $3242.400 \mathrm{kPa}$. Therefore, the valve starts opening while the rotation angle of the piston reaches $212^{\circ}$ where the pressure of compression chamber at Inner 2 , is larger than $3200 \mathrm{kPa}$, shown in Figure $7 \mathrm{~b}$. With continuous compression, the pressure of compression chamber reaches its maximum, $4324.530 \mathrm{kPa}$ while the piston rotation angle is at $258^{\circ}$. However, the maximum openness of reed valve is reached over $3^{\circ}$, while the rational angle of piston is $277^{\circ}$. There is a time lag between the maximum opening of reed valve, and the maximum pressure, due to the magnitude of moment inertia of reed valve. For a given pressure exerting on valve, the moment of inertia of valve 
decides the angular acceleration of valve motion, which in turn affects the time required to reach the maximum openness as described by Equation (7). Hence, for a given pressure or torque exerting on the valve, the larger moment of inertia of valve results in smaller the angular acceleration of valve, and vice versa. This problem will be discussed further in the Section 4.4.

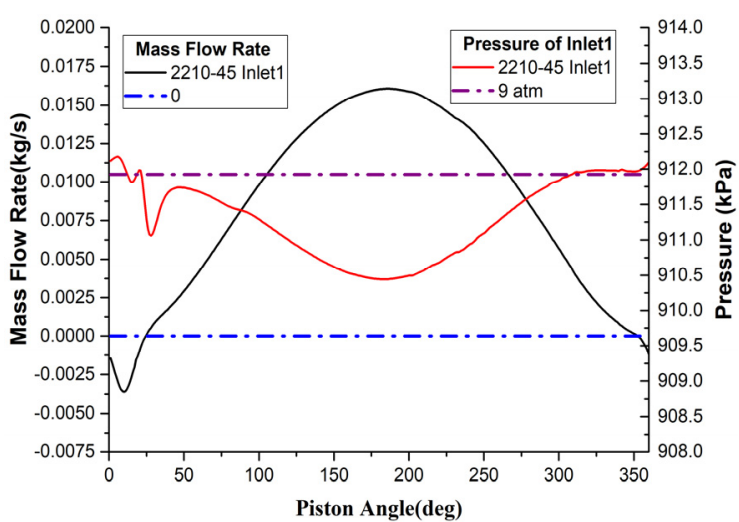

(a)

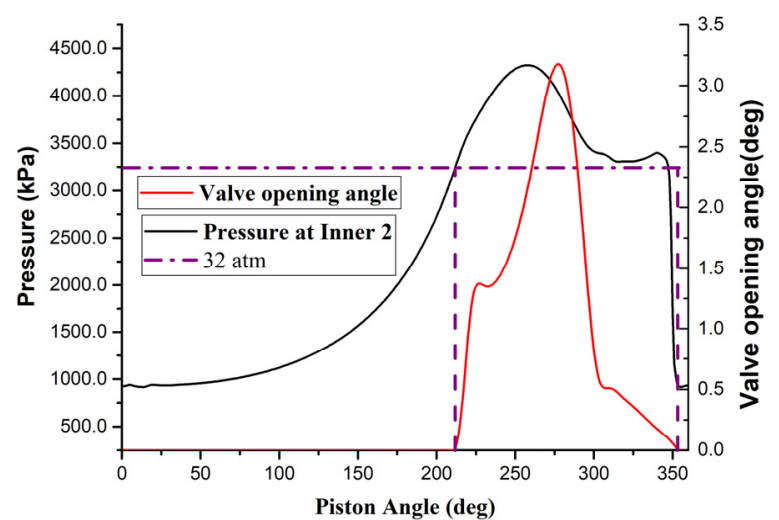

(b)

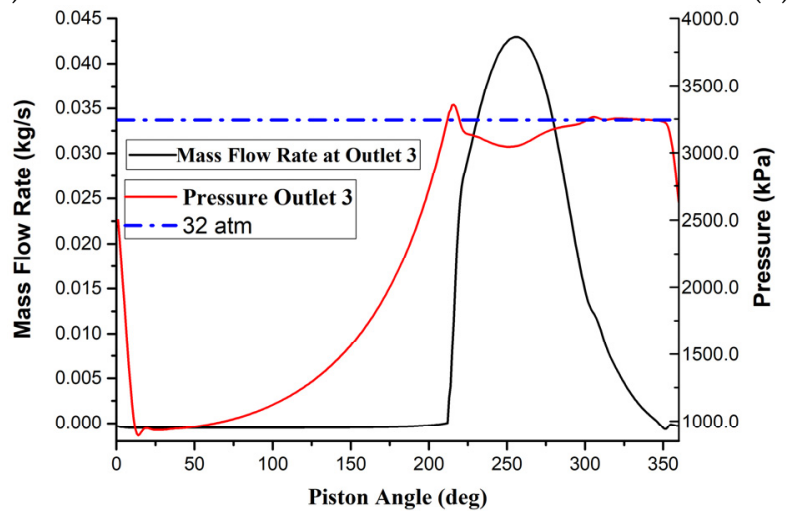

(c)

Figure 7. Physical properties of basic type, model 2210-45: (a) mass flow rate and pressure at Inlet 1, (b) pressure of compression chamber at Inner 2 and opening angle of reed valve, (c) discharge mass flow rate and pressure at Outlet 3.

The pressure at the Outlet 3 is close to the required pressure, $3242.400 \mathrm{kPa}$, shown in Figure 7c. However, when piston rotation angle is between $220^{\circ}$ to $300^{\circ}$, the pressure at Outlet 3 is lower than the required pressure but discharge mass flow rate reaches its maximum at $256^{\circ}$ of rotation angle of piston. This is because that partial pressure energy is converted into kinetic energy and results in a higher flow velocity, as well as a larger mass flow rate at the discharge port once the reed valve is opened. This discharge pressure profile relationship with piston rotation angle is similar to the result of Liang et al. [1]. As the piston rotates, pressure of compression chamber and discharge pressure are changed periodically as shown in Figures $8 \mathrm{a}$ and $8 \mathrm{~b}$, respectively. The refrigerant enthalpies at inlet/outlet and mass flow rate are shown in Figure 9a. Figure 9 b shows a cycle of the instantaneous rate of work done on the refrigerant at any rotation angle of piston as calculated using Equation (8) based on the data from Figure 9a.

The basic physical properties are obtained from the analyses above. Figure 7a shows the amount of mass flow rate sucked into the compressor and the magnitude of suction pressure. Figure $7 \mathrm{~b}$ shows how chamber pressure reacts on the motion of reed valve. Figure $7 \mathrm{c}$ indicates whether the rated pressure at outlet is reached. The enthalpy change between inlet and outlet is shown in Figure 9a which is important data for calculating the work done the refrigerant in Figure 9b. Once these basic data are 
obtained, the efficiency of compressor is acquired. The following studies will be conducted with the same criteria to determine the effects of volume, inlet angle, and mass of valve on the efficiency.

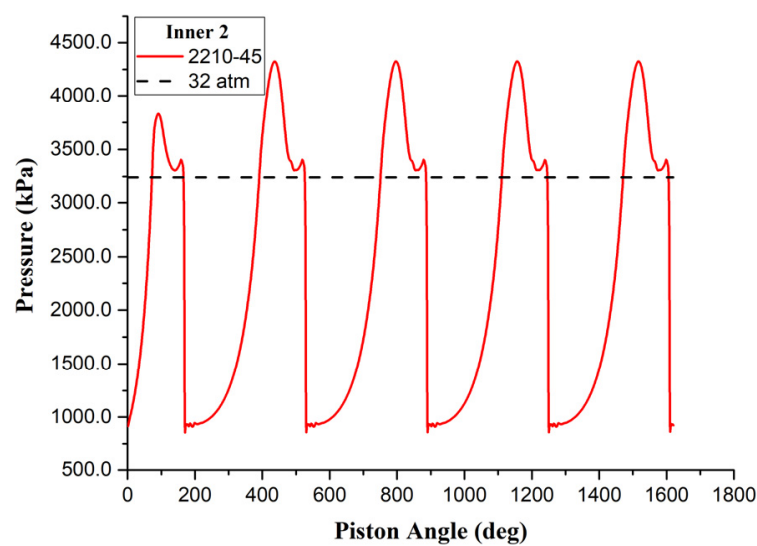

(a)

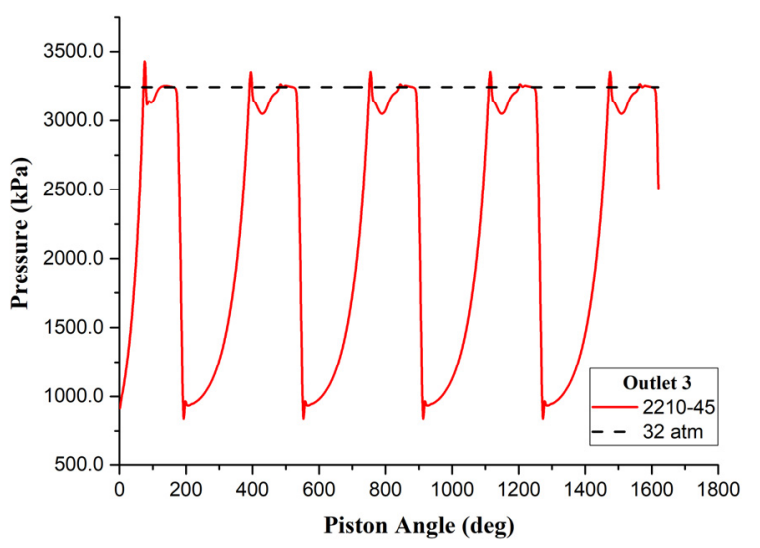

(b)

Figure 8. Pressure variation during a serial of cycles: (a) pressure of compression chamber measured at Inner 2, (b) discharge pressure measured at Outlet 3.

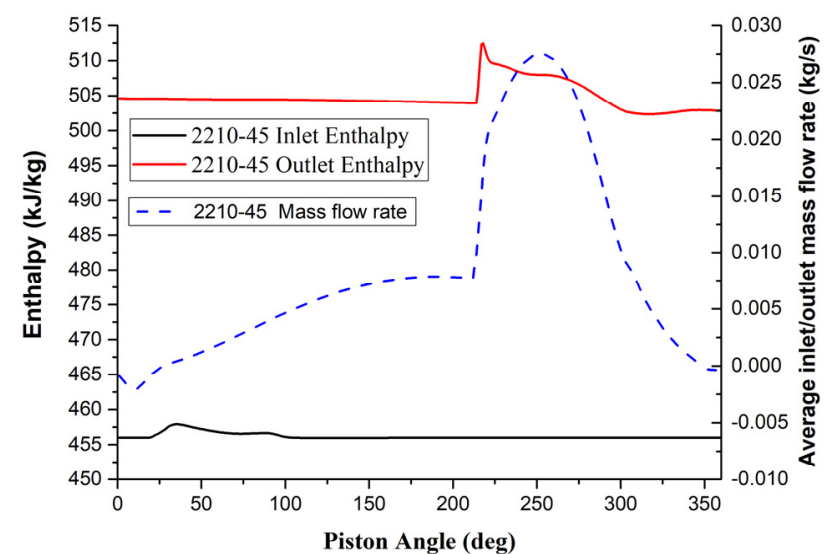

(a)

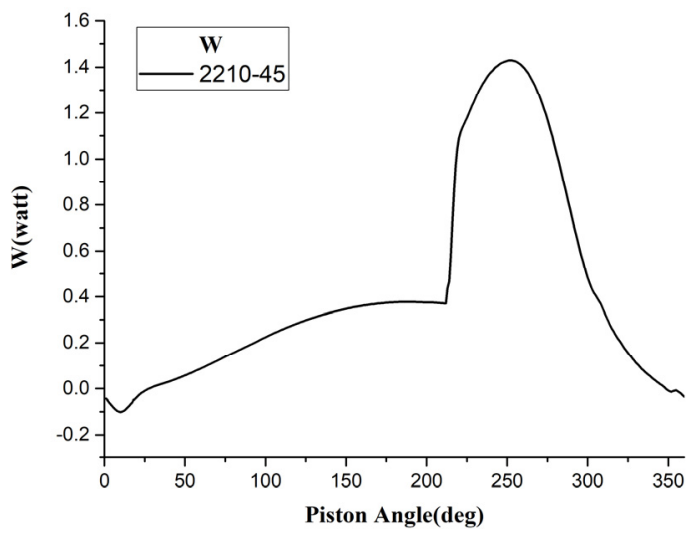

(b)

Figure 9. Enthalpy and work: (a) enthalpy at inlet/outlet and average mass flow rate, (b) instantaneous work done on the refrigerant.

\subsection{Flow Phenomena}

When the piston rotation angle is at $0^{\circ}$, the piston pushes the sliding blade into the slot inside the wall of cylinder. At this moment, the whole cylinder becomes an entire chamber where the refrigerant flows in from inlet and goes through the chamber to the reed valve as shown in Figure 10a. Although at this moment the reed valve is closed, the reed valve is not shut up completely tight due to the limit of manufacturing. Hence, the reverse flow leaks through the gap between reed valve and rim of discharge port from the outside of compressor, where the pressure $(3242.400 \mathrm{kPa})$ is higher than that inside the chamber $(<911.925 \mathrm{kPa})$. The reverse flow becomes a jet flow causing a pair of vortices inside the chamber as shown in Figure 10a.

As the piston rotates to between $40^{\circ}$ and $80^{\circ}$ as shown in Figure $10 \mathrm{~b}, \mathrm{c}$, the sliding blade and wall of piston separates the cylinder into suction and compression chambers. In the compression chamber, the rolling piston drives the refrigerant flows at the same velocity, but refrigerant velocity on the wall of cylinder is zero. Therefore, the large flow velocity gradients between the piston and the 
wall of cylinder causes an obvious swirl. During the compression, in suction side, the refrigerant is continuously sucked into chamber.

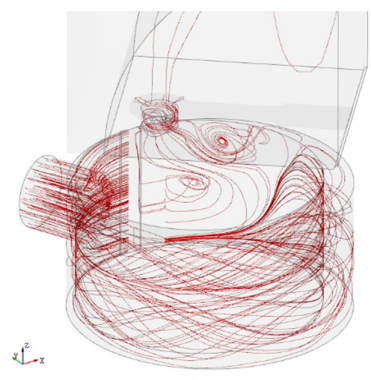

(a)

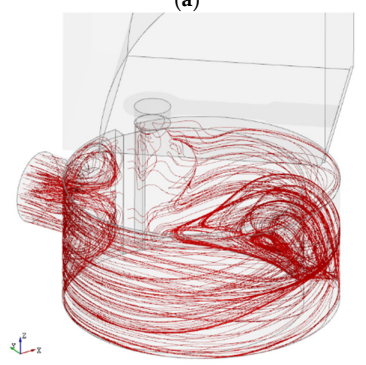

(c)

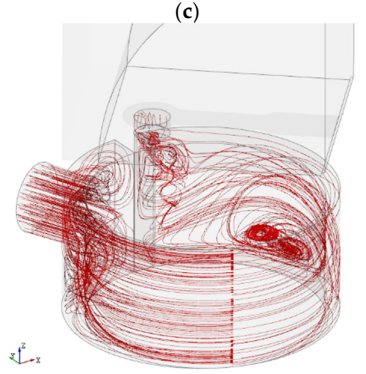

(e)

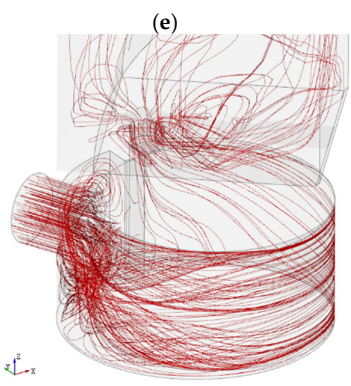

(g)

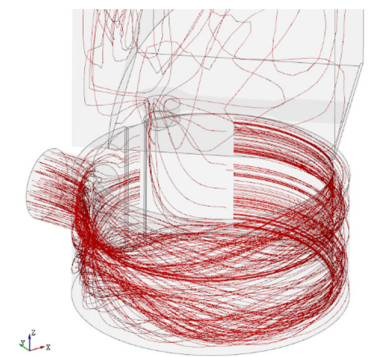

(i)

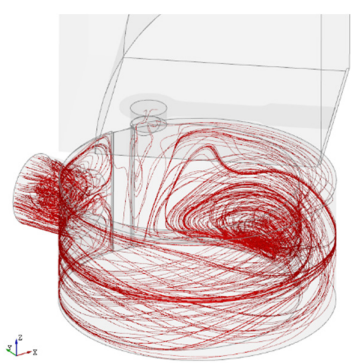

(b)

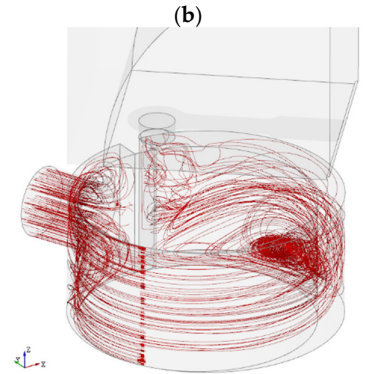

(d)
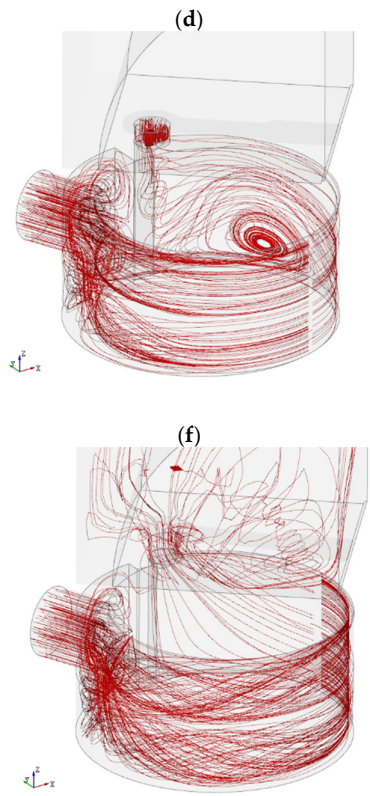

(h)

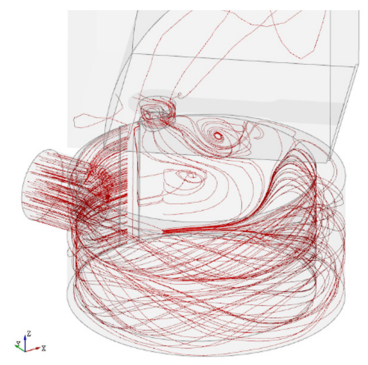

(j)

Figure 10. Streamlines at different rotation angles of piston: (a) $0^{\circ}$, (b) $40^{\circ}$, (c) $80^{\circ}$, (d) $120^{\circ}$, (e) $160^{\circ}$, (f) $200^{\circ}$, (g) $240^{\circ}$, (h) $280^{\circ}$, (i) $320^{\circ}$, (j) $360^{\circ}$. 
When the piston rotation angle is at $120^{\circ}$, obviously, the streamlines are divided by piston into two parts, which are suction and compression, respectively, as shown in Figure 10d. A large swirl still exists in the compression chamber near the outlet. While the piston rotation angle is between $160^{\circ}$ and $200^{\circ}$, the swirl still exists but its magnitude is reduced somewhat as shown in Figure 10e,f. This is due to the shrinkage of compression chamber. Once the pressure is built up and finally exceeds the required pressure, $3242.400 \mathrm{kPa}$, the reed valve opens and the swirl disappears as shown in Figure $10 \mathrm{~g}-\mathrm{i}$. The swirl may be the one of factors cause noise problem.

The preceding section and Figure 10 are the analysis and flow visualization for a basic model of compressor. This paper also attempted to determine effects of other geometric parameters such as the volume of compressor and inlet angle on the efficiency. Mass of reed valve was also changed to determine how moment of inertia affected the response of the reed valve.

\subsection{Volume Effect}

Designing different volumes of compressor to meet the various compression requirements is usually demanded. For increasing the working volume without changing the external dimension of compressor due to the limited space inside an air conditioner, decreasing the diameter of piston is one of the options to meet this requirement. Therefore, it is crucial to study the working volume effect on efficiency. The volume was varied from $-15 \%$ to $+15 \%$ of the basic model, Type $2210-45$. The volume was varied by changing the piston diameter and its associated eccentricity only, whereas the dimension of cylinder, sliding blade, and piston rotational speed are remained unchanged as shown in Table 4 and Figure 11. With the same dimension of cylinder, the piston is shrunk to increase the working volume, and vice versa.

Table 4. Different working volumes of compressor.

\begin{tabular}{cccccccc}
\hline Type & $\mathbf{2 2 1 0 - 4 5}$ & $\mathbf{+ 5 \%}$ & $\mathbf{+ 1 0 \%}$ & $\mathbf{+ 1 5 \%}$ & $\mathbf{- 5 \%}$ & $\mathbf{- 1 0 \%}$ & $\mathbf{- 1 5 \%}$ \\
\hline Volume $\left(\mathrm{mm}^{3}\right)$ & 5049 & 5301 & 5553 & 5806 & 4796 & 4544 & 4291 \\
\hline Piston radius $(\mathrm{mm})$ & 16.45 & 16.311 & 16.171 & 16.029 & 16.588 & 16.725 & 16.861 \\
\hline Eccentricity $(\mathrm{mm})$ & 2.567 & 2.706 & 2.847 & 2.988 & 2.429 & 2.292 & 2.156 \\
\hline
\end{tabular}

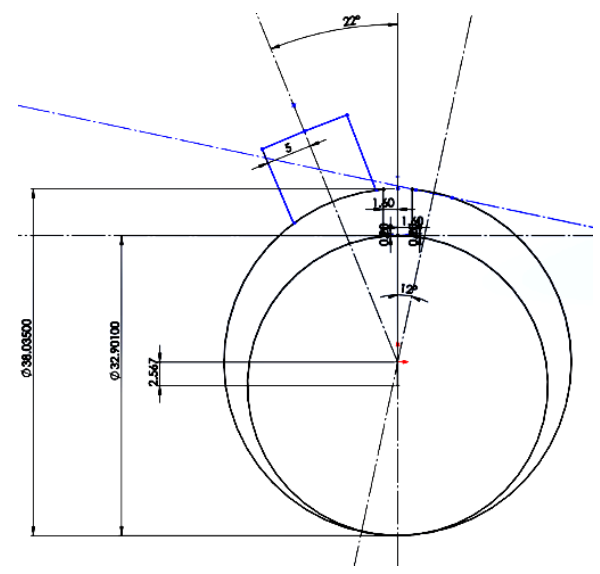

(a)

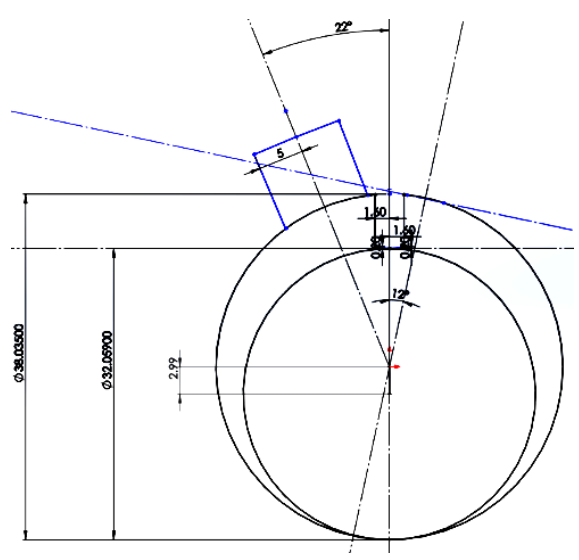

(b)

Figure 11. Two different volumes of compressor: (a) original type, 2210-45, (b) original type with additional $15 \%$ of volume.

The mass flow rate at the inlet and the suction pressure both increase as the volume of compressor increases, as shown in Figure 12a. The suction pressure is relative to the inlet ambient pressure, 911.925 $\mathrm{kPa}$ and the larger volume results in greater suction pressure, which leads to a larger mass flow rate at the inlet. The pressure of compression chamber at Inner 2 increases as the volume of compressor increases, as shown in Figure $12 \mathrm{~b}$ where the overshoot pressure which is relative to the rated pressure, 
also increases with volume. The opening angle of reed valve increases as the volume of compressor increases, as shown in Figure 12b. The period of opening angle of reed valve, which is larger than 3 , is prolonged; however, the range of piston rotation angle during the open status of reed valve is not affected much by the changing in volume. The pressure of compression chamber at Inner 2 varies periodically with the rotation of piston as shown in Figure 12c, which indicates the pressure of compression chamber varies between $927 \mathrm{kPa}$ and $4617 \mathrm{kPa}$. The discharge mass flow rate increases proportionally as the volume of compressor increases, as shown in Figure 12d. However, the discharge pressure does not change much with the compressor volume and is only slightly lower than the rating pressure due to the larger velocity of flow at the discharge port.

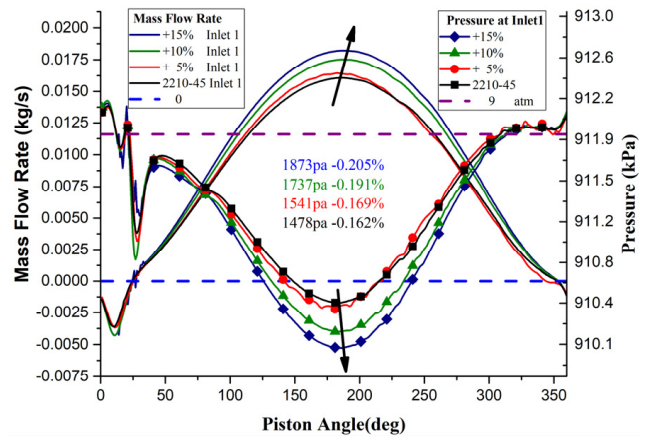

(a)

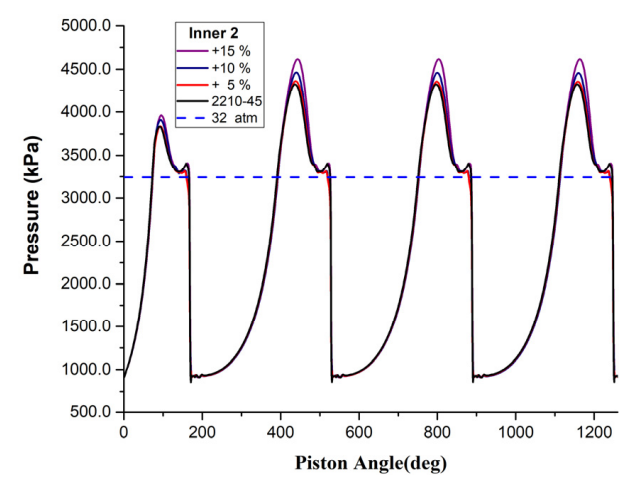

(c)

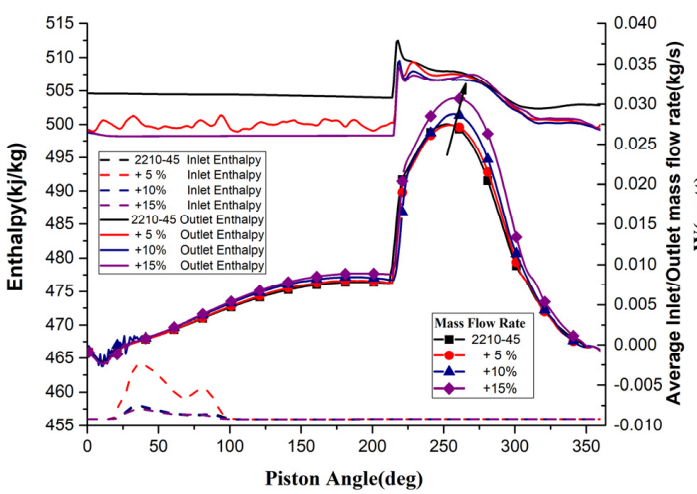

(e)

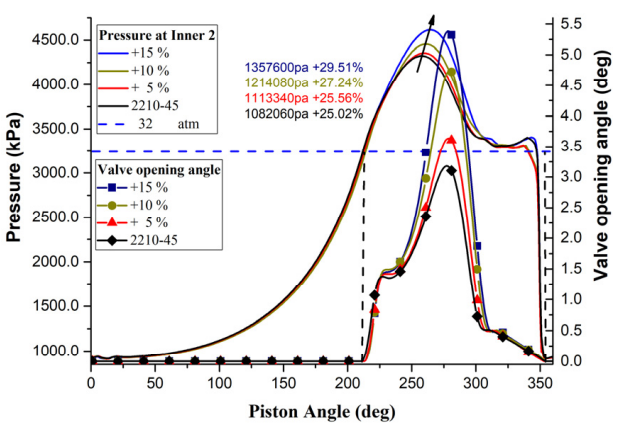

(b)

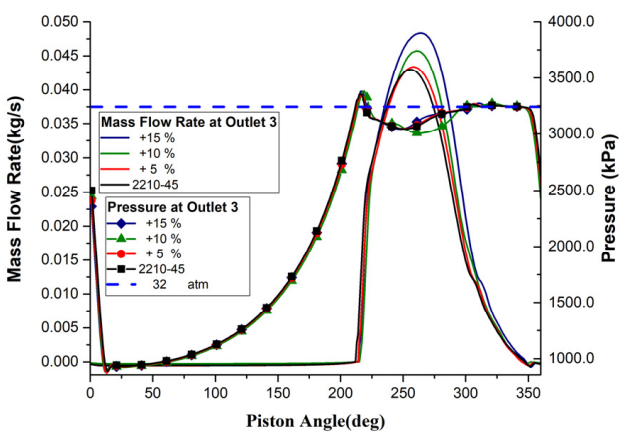

(d)

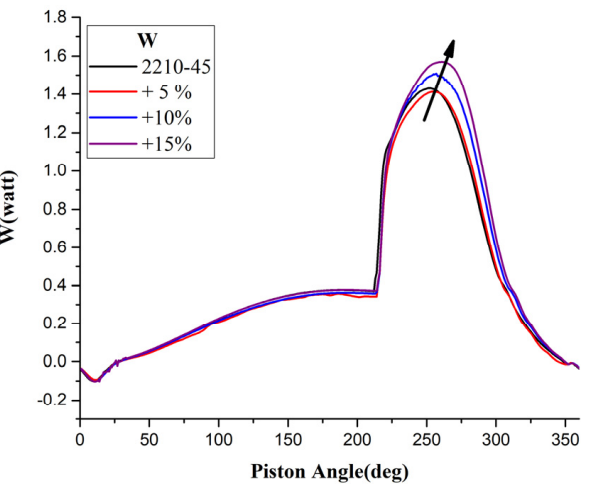

(f)

Figure 12. Physical properties of different volumes by increasing original one up to $15 \%$ in $5 \%$ increment: (a) mass flow rate and pressure at Inlet 1 (b) pressure of compression chamber at Inner 2 and opening angle of reed valve (c) pressure variation at Inner 2 during a serial cycles (d) discharge mass flow rate and pressure at Outlet 3 (e) enthalpy at inlet/outlet and average mass flow rate (f) instantaneous rate of work done on the refrigerant. 
Figure 12e shows the enthalpies at the inlet and outlet are about $455 \mathrm{~kJ} / \mathrm{kg}$ and $502 \mathrm{~kJ} / \mathrm{kg}$, respectively. Noticeably, the enthalpy at outlet decreases as the volume of compressor increases. This is because the larger volume is compressed by a smaller piston over the same period of time. However, the increase of the mass flow rate due to the increase of volume compensates for the decrease of enthalpy at the outlet. Therefore, the work done on the refrigerant is increased as the volume of compressor increases, as shown in Figure 12f.

The second part of this section is to study the change due to the decrease in working volume. The diameter of piston is increased to reduce the volume of compressor from $-5 \%$ to $-15 \%$ of the original one, 2210-45. The trends of the results for the reduced volume model are almost opposite to those where volume increased. The mass flow rate of refrigerant and suction pressure at Inlet 1 both decrease as the volume decreases, as shown in Figure 13a. Pressure in the compression chamber at Inner 2 decreases as the volume of compressor decreases, as shown in Figure 13b, where the overshoot of the rated pressure also decreases as the volume of compressor decreases. The lower pressure of compression chamber results in a smaller opening angle of reed valve as the volume of compressor decreases, shown in Figure 13b. The discharge mass flow rate decreases proportionally when the volume of compressor decreases, shown in Figure 13c, which also indicates that the discharge pressure does not change much with compressor volume. The enthalpy and mass flow rate both decrease as the volume of compressor decreases, as shown in Figure 13d. Hence, as the volume of compressor decreases, the work done on refrigerant decreases, as shown in Figure 13e.

Figure $13 \mathrm{f}$ shows that input power and work done on the refrigerant both increases proportionally with the volume of compressor. The overall efficiency of the compressor is about 64 to $69 \%$. Among the types tested, the original type, $2210-45$ possesses the highest efficiency, $69 \%$, because more work is done on the refrigerant. Hence, there is an optimal diameter ratio of piston to cylinder, which preserves the highest efficiency.

For some manufacturing reasons, the inlet angle is usually demanded to deviate away from the sliding blade with an enough distance. Hence, the inlet angle is changed significantly to look for the design margin. The inlet angle is varied from $15^{\circ}$ to $45^{\circ}$ to determine any effect on the compressor. The mass flow rate at the inlet and suction pressure both does not change significantly with the inlet angle, as shown in Figure 14a. However, the larger inlet angle results in greater fluctuations of the pressure at the inlet as piston rotates between $0^{\circ}$ and $56^{\circ}$. As the fluctuated pressure greater than the inlet ambient pressure, it causes a reverse flow at the inlet. The reverse mass flow rate is increased as the inlet angle becomes greater. The inlet angle affects the overshoot of rated pressure slightly, as shown in Figure 14b, however, the opening angle of reed valve decreases as the inlet angle of compressor increases. This is due to the larger inlet angle shortening the travel distance for compression. This also explains why the pressure of compression chamber at Inner 2 is slightly lower, and the enthalpy at Outlet 3 becomes smaller for larger inlet angle, as shown in Figure 14b,c. As a result, the work done on refrigerant decreases when the inlet angle increases, as shown in Figure 14d. The input power and work done on the refrigerant decreases when the inlet angle increases, as shown in Figure 14e. Among these cases, work done on refrigerant reaches a maximum when inlet angle is at $22^{\circ}$ and results in the maximum efficiency. Figure 14e suggests a design margin for this type of compressor, that is, the inlet angle should be greater than $15^{\circ}$, but less than $30^{\circ}$. 


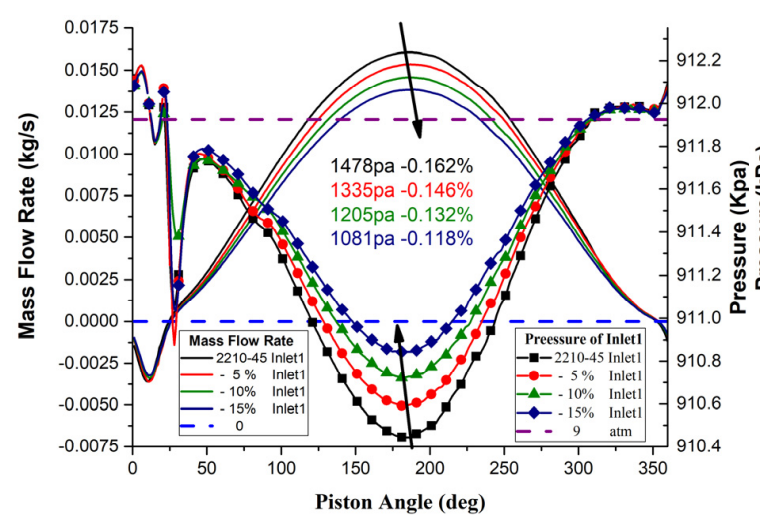

(a)

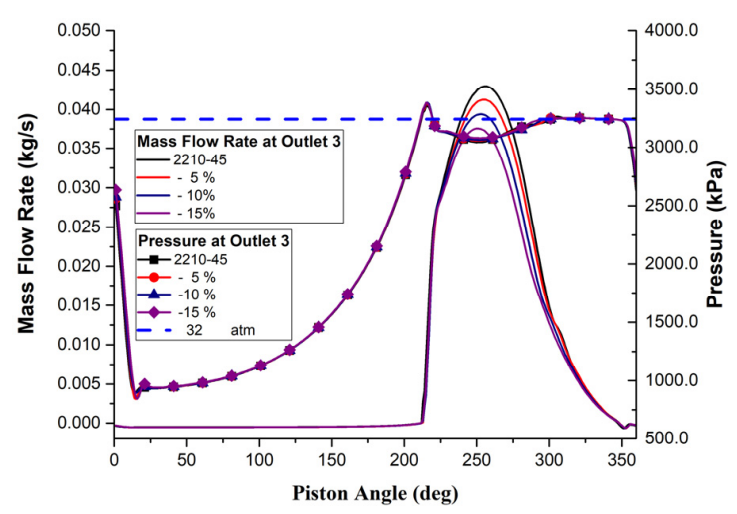

(c)

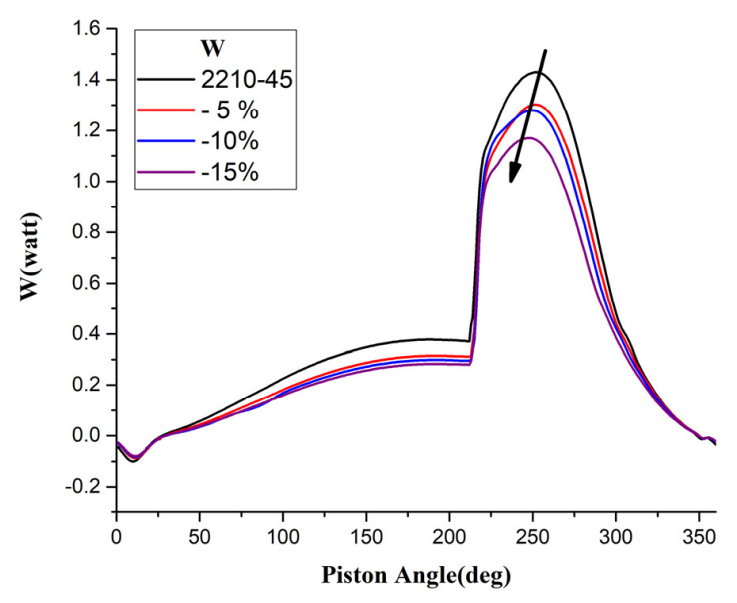

(e)

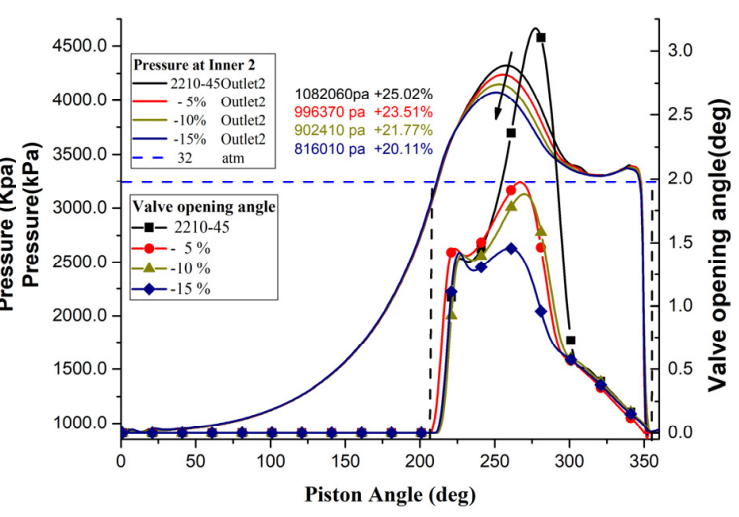

(b)

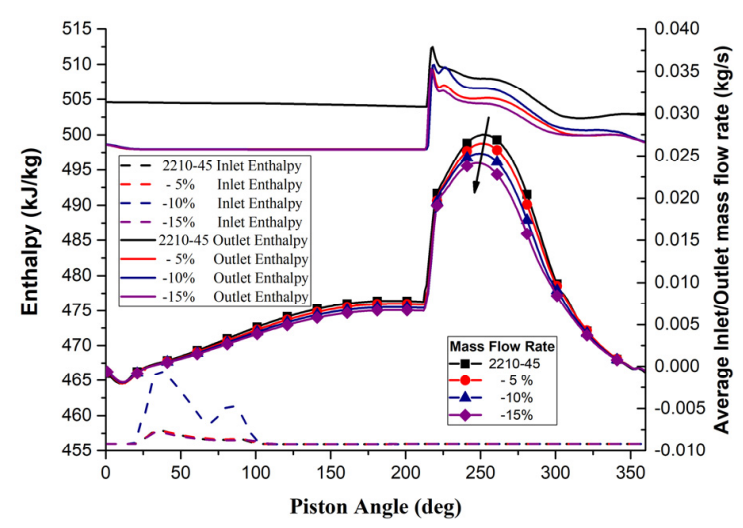

(d)

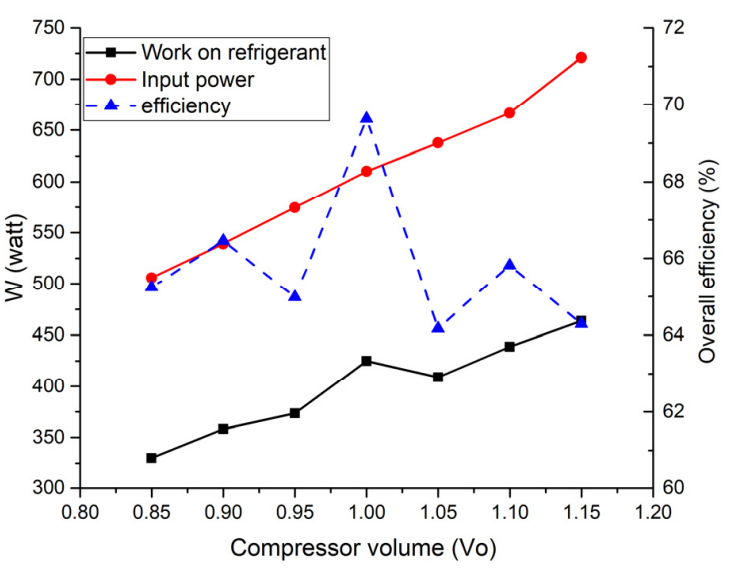

(f)

Figure 13. Physical properties of different volumes by decreasing original one up to $-15 \%$ in $5 \%$ decrement: (a) mass flow rate and pressure at Inlet 1; (b) pressure of compression chamber at Inner 2 and opening angle of reed valve; (c) discharge mass flow rate and pressure at Outlet 3 ; (d) enthalpy at inlet/outlet and average mass flow rate, (e) instantaneous rate of work done on the refrigerant, (f) mean work done on the refrigerant, input power and overall efficiency, Vo is the volume of original type, 2210-454.4. Inlet Angle Effect. 


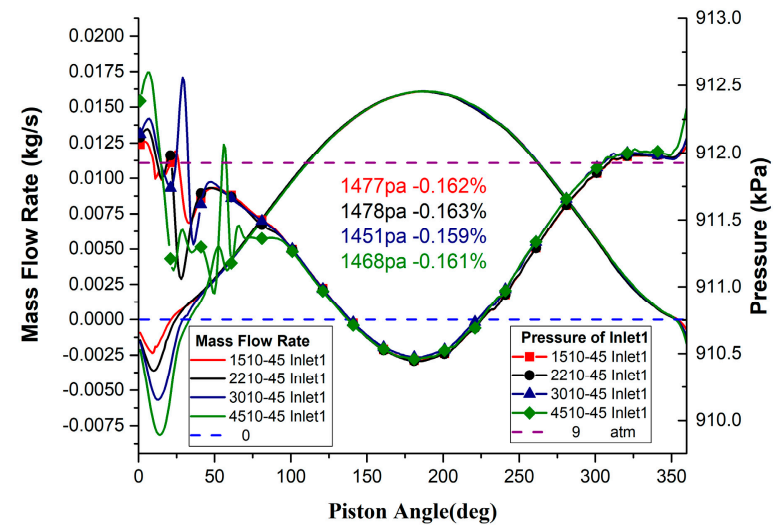

(a)

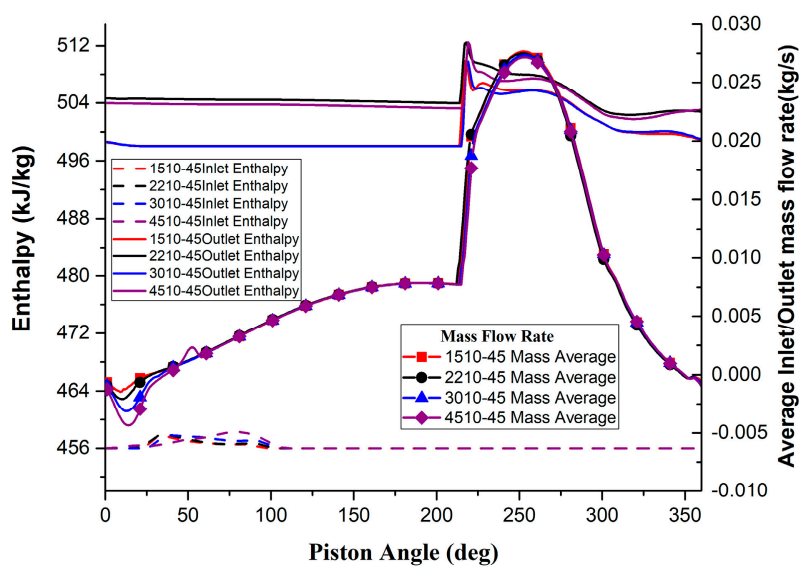

(c)

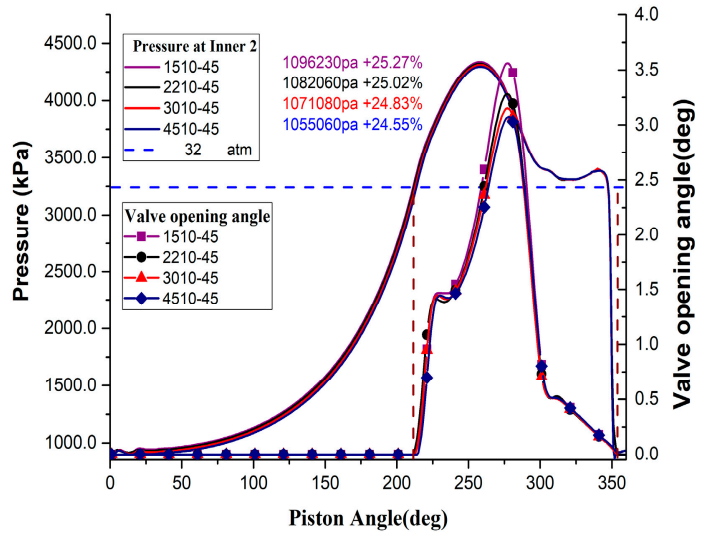

(b)

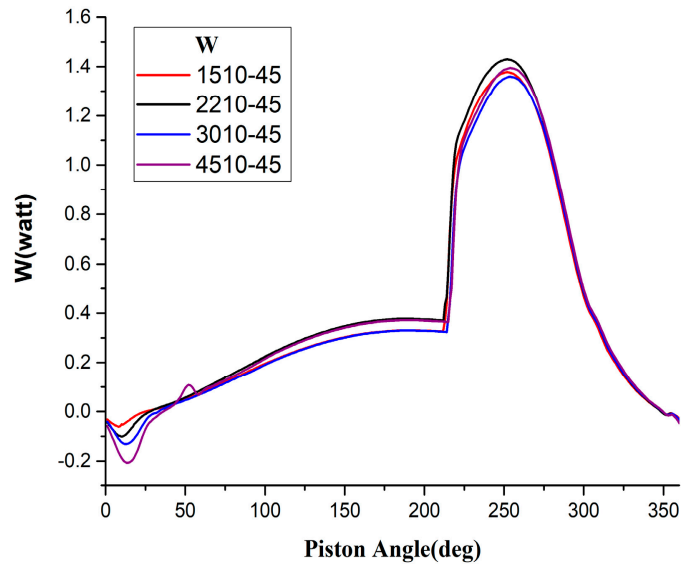

(d)

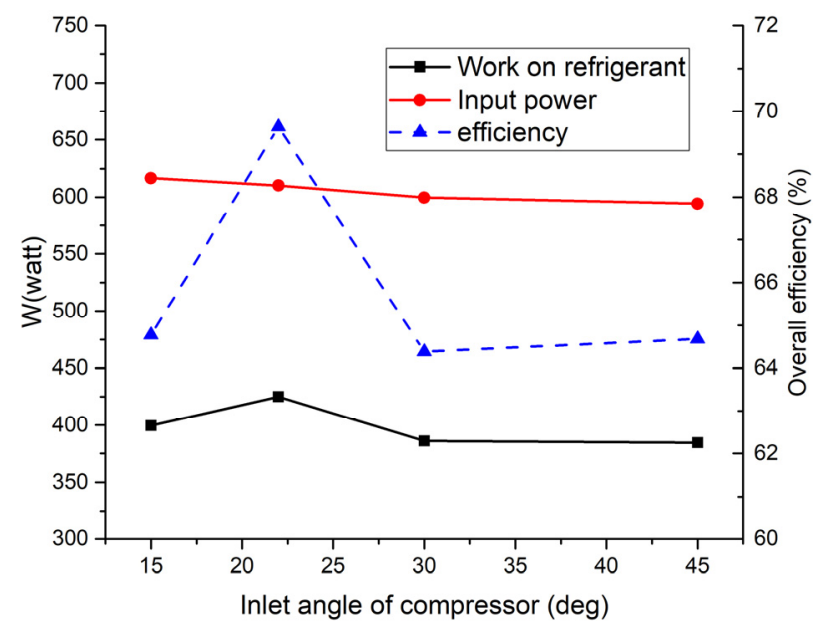

(e)

Figure 14. Physical properties arising from different inlet angles, $\alpha=15^{\circ}$ to $45^{\circ}$ : (a) mass flow rate and pressure at Inlet 1, (b) pressure of compression chamber at Inner 2 and opening angle of reed valve, (c) enthalpy at inlet/outlet and average mass flow rate, (d) instantaneous rate of work done on the refrigerant, and (e) mean work done on the refrigerant, input power and overall efficiency. 


\subsection{Mass of Reed Valve Effect}

The agility of reed valve affects the effective flow area of a compressor [9]. Hence, it is important to understand the speed of response of reed valve. In this study, the mass of reed valve is varied from 20 to 40 times of that of the original to determine any effect on the discharge pressure and motion of valve, due to the changes in moment of inertia. Noticeably, the suction pressure is reduced by $50 \%$ from $1478 \mathrm{~Pa}$ for original to $736 \mathrm{~Pa}$ when mass is increased more than 20 times, as shown in Figure 15a. In addition, when piston rotates between $\theta=0$ and 40 , the pressure at the inlet port is greater than the inlet ambient pressure, $911.925 \mathrm{kPa}$. When piston rotates at $\theta=24$, the pressure at the point of Inlet 1 is about 5.624 to $6.886 \mathrm{kPa}$ higher than the inlet ambient pressure. This means that the refrigerant may be pushed out from the inlet because of pressure difference. The higher pressure at the inlet port mainly arises due to the leakage from the increased mass of valve. Figure $15 \mathrm{~b}$ shows the overshoot of rated pressure at Inner 2 increases slightly, from $25.02 \%$ to $27.96 \%$ due to the mass increase, however, the motion of valve is changed tremendously. The opening angle of valve is increased from 3 on the original to 6 , where 40 times mass is used. In addition, the period of the valve in opening status is longer where mass is greater because of larger moment of inertia. There is a smaller angular acceleration of valve under the same pressure force as described by Equation (7). Thus larger mass of reed valve delays more phase angle of rotation to close as shown in Figure 15b. The beginning of opening valve is the same for all cases at $\theta=212$. However, the closing phase angle are distinct for each case, which is from $\theta=0$ for the original model to $\theta=21$ for the case of 40 times mass of the original valve. The enthalpy at outlet is reduced as the mass of reed valve increases because greater resistance to open the valve causes a leakage from the compression chamber to the suction chamber, as shown in Figure 15c. The leakage also causes a higher pressure at the inlet and results in reverse mass flow rate at $\theta=0$ to 20, as shown in Figure 15a,c.

Though the maximum of work done on refrigerant increase with an increase in mass of valve, there is negative work at $\theta=0$ to 20 , because of reverse flow at Inlet 1 shown in Figure $15 \mathrm{~d}$. The mean work done on refrigerant in one cycle roughly decreases, but input power increases as the mass of valve increases. The input power increases to overcome the resistance caused by the greater valve mass. However, the longer time of valve in opening reduces the work done on refrigerant and more power consumption as shown in Figure 15e. Therefore, the efficiency is reduced as the mass of valve increases. Figure 15e indicates the lighter reed valve leads to higher efficiency of compressor, without considering deflection. However, this is constrained by manufacturing limits and the expected life cycle.

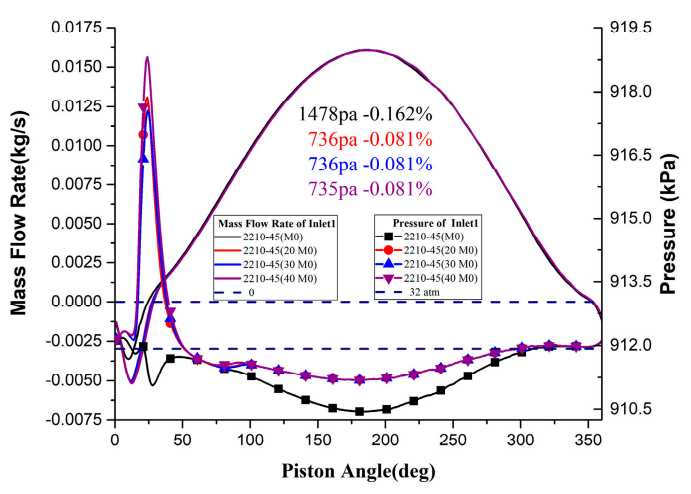

(a)

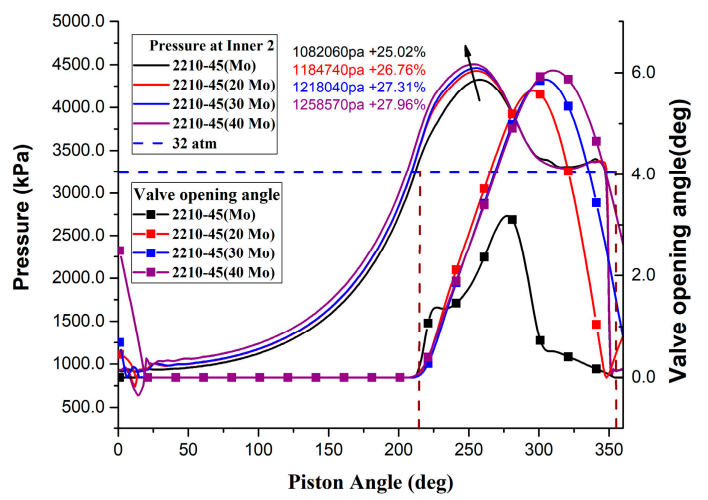

(b)

Figure 15. Cont. 


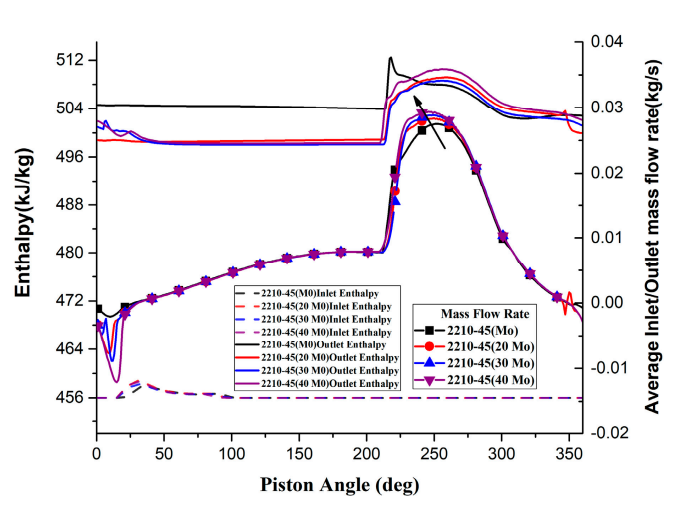

(c)

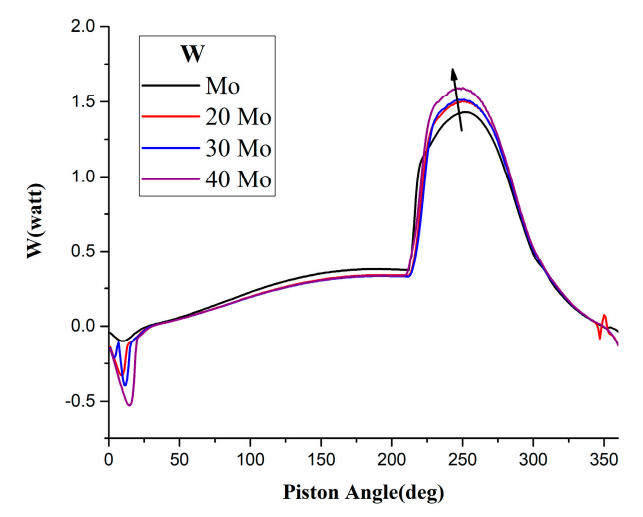

(d)

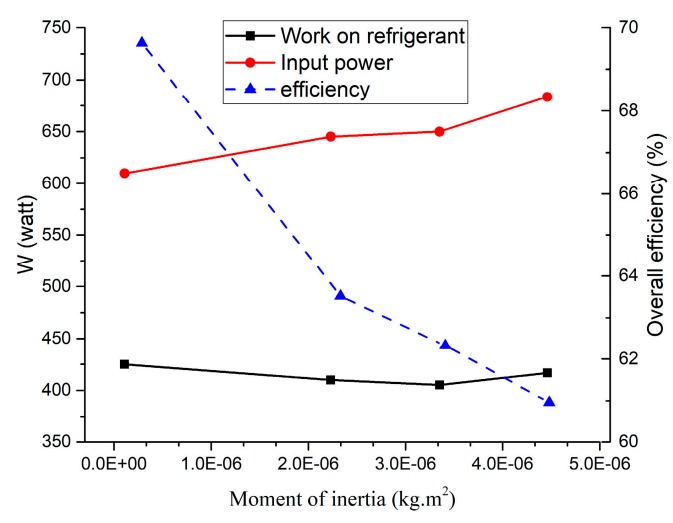

(e)

Figure 15. Physical properties due to change of mass of reed valve, from the original to 40 times mass: (a) mass flow rate and pressure at Inlet 1, (b) pressure of compression chamber at Inner 2 and opening angle of reed valve, (c) enthalpy at inlet/outlet and average mass flow rate, (d) instantaneous rate of work done on the refrigerant, (e) mean work done on the refrigerant, input power and overall efficiency; Mo is the mass of reed valve of original type: 2210-45.

\section{Conclusions}

The input power and work done on the refrigerant both increases proportionally with the volume of compressor; however, the maximum efficiency exists in the original 2210-45 device.

1. Greater inlet angle causes a larger amount of reverse flow at the inlet. This causes a decrease of the work done on refrigerant. Among those, the inlet angle at 22 provides the best efficiency of compression. The suggested inlet angle is $15<\alpha<30$.

2. The larger mass of reed valve causes the valve to open for longer and with a larger angle of opening. More input power is required to overcome increased resistance due to increased mass of valve, leading to a decrease in efficiency.

3. A large swirl exists in the compression chamber as the piston rotation angle exceeds $120^{\circ}$. Once the reed valve opens, the swirl disappears. The swirl may be one of the factors cause noise problems.

4. Although the original type, 2210-45 so far offers an optimal performance, it has come as a product of many trial and error in manufacturing. The results of this study show CFD techniques can provide a more economical approach for engineering and design of rolling piston type of compressors.

In summary, this study provides a method to increase the working volume of compressor without changing the external dimension of compressor due to considering the limited space inside an air conditioner. However, there is an optimal diameter ratio of piston to cylinder, which preserves the highest efficiency. For some manufacturing reasons, the inlet angle is demanded to be far enough away from the sliding blade of compressor. This study provides a design margin for inlet angle to keep enough 
space from the sliding blade without losing efficiency. A larger mass of reed valve for the compressor reduces the work done the refrigerant and increases the power consumption. Under the allowance of manufacturing, the results suggest using the lighter reed valve can keep higher efficiency. The study also shows the CFD technique provides a more efficient approach for the design of compressor. The flow visualization by simulation diagnoses the potential factors, which cause the problems, such as noise.

Author Contributions: L.-C.H. conceived, designed the simulations and wrote the paper; G.-W.W. and P.-J.L. performed the simulations; F.-S.H. and Y.-C.C. conducted the experiments. All authors have read and agreed to the published version of the manuscript.

Funding: New Widetech Industries Co., Ltd., grant No. 105-149.

Acknowledgments: The authors are grateful to New Widetech Industries Co., Ltd., for their financial support under grant No. 105-149.

Conflicts of Interest: The authors declare no conflict of interest.

\section{References}

1. Liang, S.; Xia, S.; Kang, X.; Zhou, P.; Liu, Q.; Hu, Y. Investigation of refrigerant flow simulation and experiment of rolling piston. In Proceedings of the International Compressor Engineering Conference, West Lafayette, IN, USA, 12-15 July 2010.

2. Ba, D.-C.; Deng, W.-J.; Che, S.-G.; Li, Y.; Guo, H.-X.; Li, N.; Yue, X.-J. Gas dynamics analysis of a rotary compressor based on CFD. Appl. Therm. Eng. 2016, 99, 1263-1269. [CrossRef]

3. Ishii, N.; Fukushima, M.; Yamarnura, M.; Fujiwara, S.; Kakita, S. Optimum combination of dimensions for high mechanical efficiency of a rolling-piston rotary compressor. In Proceedings of the International Compressor Engineering Conference, West Lafayette, IN, USA, 17-20 July 1990.

4. $\quad$ Noh, K.-Y.; Min, B.-C.; Song, S.-J.; Yang, J.-S.; Choi, G.-M.; Kim, D.-J. Compressor efficiency with cylinder slenderness ratio of rotary compressor at various compression ratios. Int. J. Refrig. 2016, 70, 42-56. [CrossRef]

5. Bolloju, S.R.K.; Tiruveedhula, V.; Munnangi, N.; Vaddadi, K.R.; Reddy, M.P. Efficiency improvement of rotary compressor by improving the discharge path through simulation. In Proceedings of the International Compressor Engineering Conference, West Lafayette, IN, USA, 14-17 July 2014.

6. Tan, Q.; Liu, Z.; Cheng, J.; Feng, Q. Effective flow and force areas of discharge valve in a rotary compressor. In Proceedings of the International Compressor Engineering, West Lafayette, IN, USA, 14-17 July 2014.

7. Brancher, R.D.; Deschamps, C.J. Modeling of rolling-piston compressors with special attention to the suction and discharge processes. In Proceedings of the International Compressor Engineering Conference, West Lafayette, IN, USA, 14-17 July 2014.

8. Prater Jr, G.; Hnat, W.P. Optical measurement of discharge valve modal parameters for a rolling piston refrigeration compressor. Measurement 2003, 33, 75-84. [CrossRef]

9. Liu, C.H.; Geng, W. Research on suction performance of two-cylinder rolling piston type rotary compressors based on CFD simulation. In Proceedings of the International Compressor Engineering Conference, West Lafayette, IN, USA, 12-15 July 2004.

10. Cai, D.; He, G.; Yokoyama, T.; Tian, Q.; Yang, X.; Pan, J. Simulation and comparison of leakage characteristics of R290 in rolling piston type rotary compressor. Int. J. Refrig. 2015, 53, 42-54. [CrossRef]

11. Ooi, K.T. Design optimization of a rolling piston compressor for refrigerators. Appl. Therm. Eng. 2005, 25, 813-829. [CrossRef]

12. Launder, B.E.; Spalding, D.B. The numerical computation of turbulent flows. Comput. Methods Appl. Mech. Eng. 1974, 3, 269-289. [CrossRef]

13. Lemmon, E.W.; Bell, I.H.; Huber, M.L.; McLinden, M.O. NIST Standard Reference Database 23: Reference Fluid Thermodynamic and Transport Properties-REFPROP, Version 10.0, National Institute of Standards and Technology, Standard Reference Data Program, Gaithersburg, USA. 2018. Available online: https: //pages.nist.gov/REFPROP-docs/ (accessed on 7 April 2020).

(C) 2020 by the authors. Licensee MDPI, Basel, Switzerland. This article is an open access article distributed under the terms and conditions of the Creative Commons Attribution (CC BY) license (http://creativecommons.org/licenses/by/4.0/). 